\title{
The economic integration of Spain: a change in the inflation pattern
}

\author{
Alejandro C. García-Cintado ${ }^{1}$ Diego Romero-Ávila ${ }^{1}$ • \\ Carlos Usabiaga ${ }^{1}$
}

Received: 22 August 2015/Accepted: 13 February 2016/Published online: 2 March 2016

(C) The Author(s) 2016. This article is published with open access at Springerlink.com

\begin{abstract}
The behavior of Spanish inflation rates at the provincial level (consumption prices) differs over the two spans of time considered in our study (1955.1-1978.6, 1978.7-2014.4). We point to a long list of institutional and economic changes, at national and international levels, as the potential factors that might have led to this new pattern. In addition to confirming the remarkable persistence shown by the Spanish inflation, the PANIC (panel analysis of non-stationarity in idiosyncratic and common components) analysis we undertake identifies a higher importance of the common component of the series in the second period studied. Besides inflation, we draw attention to a battery of economic and labor variables, mostly through regional data, and we conclude that they tend to converge as well, particularly in the case of our second period of analysis. There are several theoretical avenues whereby the geographic convergence of these variables and the observed inflation convergence could be related. We also relate the common factor in inflation obtained to some potential explanatory variables. Moreover, a relevant additional analysis, which is only feasible for the second period, is implemented by focusing on the weightings attributed to the different groups of goods and services that make up the Consumer Price Index. The outcome we obtain is straightforward: the shopping basket across Spanish provinces has tended to become more homogeneous. In summary, a variety of changes, which we regard as having increased essentially since the late 70 s, with the intensification of the Spanish integration in the core of European Union, among other factors, have brought about a regime shift
\end{abstract}

Electronic supplementary material The online version of this article (doi:10.1007/s40503-016-00314) contains supplementary material, which is available to authorized users.

Carlos Usabiaga

cusaiba@upo.es

1 Universidad Pablo de Olavide, Carretera de Utrera, Km. 1, 41013 Seville, Spain 
in inflation behavior. The Spanish experience may offer lessons for other economies that follow similar paths, for instance Latin American countries.

Keywords Inflation - Economic integration - Consumer prices - Convergence · Persistence $\cdot$ PANIC methodology

\section{JEL Classification $\quad$ C23 $\cdot$ E31 $\cdot$ F15}

\section{Introduction}

This article assesses the time evolution of a fundamental economic variable, the inflation rate, for the case of the Spanish economy. More specifically, it focuses on consumption prices from a geographically disaggregated (provincial) perspective over two well-differentiated periods of time (1955.1-1978.6, 1978.7-2014.4). It is worth noting that overall Spain is a country characterized by a mild inflation differential relative to the European Economic and Monetary Union (EMU) coreCaraballo and Usabiaga (2009c). ${ }^{1}$ The analysis of the time series properties of province-level inflation rates in Spain and their convergence patterns is conducted with PANIC (panel analysis of non-stationarity in idiosyncratic and common components) as well as with the pairwise approach of Pesaran (2007a). From an econometric point of view, these provincial data allow us to build panels with higher $N$ (50 provinces instead of 17 regions) and higher $T$, which is important for the application of the PANIC methodology. ${ }^{2}$ The understanding of the behavior of provincially disaggregated inflation rate series enables us to better understand the evolution of aggregate inflation as well as to disentangle the importance of national forces from province-specific factors in explaining inflation rate variability and in identifying the sources of inflation heterogeneity. By focusing on a panel of province-level inflation rates within the same country, the identification of the province-specific idiosyncratic component and the nationally driven common component is also very important from a policy standpoint. Imagine, for instance, that the analysis gives evidence that a province like Santa Cruz de Tenerife has a strong and persistent idiosyncratic component and a weak common component. If that is the case, this would imply that policy measures implemented at regional level

\footnotetext{
1 On the price-setting process in the Spanish economy, from different perspectives, we recommend the numerous articles by Álvarez and coauthors. See, just as a sample Álvarez and Hernando (2006) and Álvarez et al. (2010).

${ }^{2}$ Romero-Ávila and Usabiaga (2012) also use, among others, these provincial inflation series to study inflation persistence. Unlike the present study that focuses on panel methods, Romero-Ávila and Usabiaga (2012) exclusively used univariate unit root tests (without considering breaks) and persistence measures like the median-unbiased estimates of the persistence parameter and the half-life of a shock. Another difference is that there, the authors studied not only provincial CPI-based inflation rates, but also aggregate, regional, and group-level CPI-based inflation rates in addition to aggregate and sectoral Producer Price Index (PPI)-based inflation rates. The evidence broadly supported the presence of a very high level of persistence, which in many instances (particularly in the case of CPI-based inflation rates) is compatible with the presence of a unit root in inflation.
} 
are required, rather than general policy measures implemented nationally or supranationally affecting all regions similarly. ${ }^{3}$

In the current scenario of EMU, it is natural to expect provincial inflation rates to be affected not only by external common shocks and national policies (e.g., fiscal policies and labor and goods market reforms), but also by such supranational policies as the common monetary policy. In that scenario, persistent inflation differentials across provinces can be conducive to different provincial interest rates, with clear implications on investment and aggregate demand. It is also appealing to focus on Spanish province-level inflation since in a currency union inflation differentials lead to realignments of the real exchange rate among provinces, which have strong implications for the relative competitiveness of the different provinces within the same country. The further disaggregation of province-level inflation rate series into the inflation rates of the 12 COICOP groups of goods and services also enables us to investigate the importance of the Balassa-Samuelson effect-and its different predictions on the behavior of the prices of goods in the tradable and nontradable sectors-across the 50 provinces forming our sample. ${ }^{4}$ According to this hypothesis, convergence among pairs of provincial inflation rates should be more prevalent in those groups involving tradable goods, since trade across provinces would help eliminate the arbitrage opportunities. In contrast, there would be less evidence of convergence among pairs of provincial inflation rates for those groups mainly composed of non-tradable goods and services. Whether regions with initially low price levels converge to higher price levels via tradables or non-tradables is also relevant for the degree of persistence of inflation differentials. If convergence operates through tradables, its implications are probably transitory, whereas if convergence works through non-tradables and the associated gradual process of productivity convergence, the implications are likely to be long-lived (Rogers 2007).

Aside from the finding supporting a lower extent of pairwise convergence for the Communications group (involving mainly non-tradables), which would accord with the Balassa-Samuelson hypothesis, the bulk of the evidence does not allow us to

\footnotetext{
3 Note that the statistical justification for using PANIC goes hand in hand with the economic intuition of the technique and the policy implications that one can derive from the results. The key is the decomposition of the observed series into a common and idiosyncratic component, and in turn the determination of their degree of integration, which enables us to establish whether idiosyncratic and/or common shocks or policies can have transitory or permanent effects on inflation, depending on the degree of integration of either component.

${ }^{4}$ It is worth recalling that in this field it is even customary to work with data from cities or municipalities. In a well-known study, Rogers (2007) works with data of cities from Europe and the USA (1990-2004). He highlights that there is a striking decline in dispersion for traded goods prices in Europe, most of which took place prior to the launch of the euro. Still, this process has not yet significantly affected the cross-city ordering of price levels. That dispersion in the euro area would be now quite close to that of the USA. Several potential factors responsible for the decline in dispersion in Europe are the harmonization of tax rates, convergence of income and labor costs, liberalization of trade and factor markets, and increased coherence of monetary policy. This study also concludes that the Balassa-Samuelson effect does not explain much of the observed inflation rate differentials across European cities. Rogers (2001, 2007) point out that despite an on-going process of convergence, deviations from the "law of one price" are still large. Factors other than price convergence explain most of the cross-country inflation differences.
} 
support the Balassa-Samuelson effect predicting important inflation differentials in non-tradables. The lessons that can be drawn from the results obtained for the Spanish provinces are also relevant for other open economies, such as several in Latin America, to the extent that they share with the Spanish economy some key features as the degree of openness, central bank behavior, fiscal policy stance, etc. The finding of widespread convergence among pairs of provincial inflation rates for both tradables and non-tradables implies that there may not be substantial regional heterogeneities in the relative productivity growth of the tradable versus the nontradable sector. This is very relevant for many Latin American countries for which real exchange rate fluctuations affect economic activity due to their specialization in commodity exports and their high dependence on imported capital goods. To the extent that there is convergence in productivity levels, the price of non-tradable goods also converges, and fluctuations in the real exchange rate across sub-national units thus fall. This would also make it easier for countries to access world financial markets in order to finance their trade imbalances, which helps smoothing consumption. Taking now a national perspective for those Latin American countries that peg their currencies to the dollar, their high volatility in productivity growth due to their high dependence on production and exports of primary goods requires high variability in domestic Consumer Price Index (CPI)-based inflation for the BalassaSamuelson hypothesis to hold. ${ }^{5}$ Hence, situations of slow growth caused by recurrent adverse supply shocks impose equilibrium domestic inflation rates below the US inflation rate. This can be achieved through a revaluation of the exchange rate or through contractionary fiscal and monetary policies, which would further harm growth and employment. These undesirable results could be prevented by adopting a flexible exchange rate regime, at the expense of the negative effects of having higher variability in the nominal exchange rate.

The use of PANIC conveys several advantages over standard methodologies employed to analyze convergence in inflation. First, it enables us to decompose the observed inflation rate series into a common and an idiosyncratic component as well as to determine the source of non-stationarity in the observed series, that is, whether it stems from the common factor(s) and/or the idiosyncratic components. Second, by allowing for common factors in the series, this technique controls for strong forms of cross-sectional dependence in the data such as cross-cointegration, which is essential to prevent severe size distortions in the tests-see O'Connell (1998), Maddala and Wu (1999) and Banerjee et al. (2005). Third, this approach is sufficiently flexible as to allow for a different order of integration in both components. Fourth, by encompassing both unit root and stationarity statistics that shift their respective null hypotheses, this framework enables us to gather confirmatory evidence on the stochastic properties of inflation. Fifth and most important, PANIC can be used as a cointegration framework without requiring the choice of a reference province in the computation of the inflation gaps, i.e., the series measuring the inflation differentials between two individual series. The

\footnotetext{
5 Drine and Rault (2003) and García-Solanes and Torrejón-Flores (2005) provide clear-cut evidence of the empirical validity of the Balassa-Samuelson hypothesis in Latin America only when panel cointegration techniques are used, whereas on a country-by-country basis the evidence is much less clear.
} 
system of the $N$ series forming each panel can be decomposed into a non-stationary part explained by the common stochastic trends $\left(\hat{r}_{1}\right)$ plus $N-\hat{r}_{1}$ cointegrating vectors involving stationary linear combinations of the individual series forming the panel. This provides information about the extent of convergence among the inflation rate series. If the evidence favors a common stochastic trend together with the existence of jointly stationary idiosyncratic series, there would be pairwise cointegration (and convergence) among individual provincial inflation rates, which would be driven by a non-stationary common factor linking all inflation rates over time.

For robustness purposes, we use an alternative test of pairwise convergence developed by Pesaran (2007a), which allows us to test whether all cross-provincial inflation differentials (pairs) are stationary with several unit root and stationarity tests. Like PANIC, this method does not require selecting a reference province in the computation of the inflation differentials between two individual series, and as such, it is not sensitive to this choice.

As already laid out, in our work we intend to shed some light upon whether there has been a change in the pattern of behavior of Spanish inflation over the last decades. In our analysis, a structural break is considered. In order to determine it endogenously, we use the procedure proposed by Lee and Strazicich (2003, LS). For the crash model the mean shift is located at July 1978. Instead of dealing with the Spanish overall inflation rate directly, we address a major geographic disaggregation. Consequently, we make use of the 50 Spanish provinces' inflation rates (excluding the Autonomous Cities of Ceuta and Melilla due to the lack of consistent data), which will compel us to employ panel data techniques (PANIC methods, in our case), thereby allowing us to capture the econometric nature of the series under study through their decomposition. Likewise, in the second part of our article our focus will be more directed towards the topic of the spatial convergence of the variable involved and its potential underlying factors-taking some relevant economic and labor variables into account, in a first step, and CPI weightings, in a second one. By and large, our analysis will show, from different viewpoints, that there has indeed existed a pattern change in that a more intense spatial convergence in inflation rates has taken place in recent decades. It bears recalling that using disaggregated data at a provincial level is not commonplace in this type of work and it is indeed less usual than concentrating on regional data, thereby rendering our results more original in this regard.

Overall, the PANIC analysis demonstrates not only the notable persistence of Spanish inflation, but also the higher importance of the common component of the series in the second period analyzed-which links provincial inflation rate series together-thereby leading to strong convergence. The evidence from the pairwise test of Pesaran (2007a) appears to largely back up these findings. Besides inflation, we focus on a battery of economic and labor variables, mostly by scrutinizing regional data, and conclude that they converge as well, mainly throughout our second period of analysis - with the exception of the real gross value added (GVA) per capita, which converges faster in the first period.

The result of high inflation persistence in Spain should not be viewed as striking, since the three most usual indicators of inflation persistence (which could be 
denoted as explicit persistence, the inflation expectation component and inflation inertia-or implicit persistence-) seem to be quite deep-seated in the Spanish economy. Thus, in this regard, the Spanish economy has long been plagued with a myriad of different types of wage and price rigidities - which give rise to a low sensitivity to the business cycle-, widespread indexation and a significant importance of backward-looking expectations, among other factors. ${ }^{6}$ Moreover, Spain is regarded as being a highly service-oriented economy, which means that labor costs account for an important fraction of total costs-the tertiary sector is known to be a labor-intensive one. This fact manifests itself as a greater persistence in final prices, with respect to other sectors whose inputs prices are proven to be more flexible. Another Spanish economy's predicament, to some extent shared with other Southern European countries, lies in the barriers to competition in certain sectors and product markets. Notwithstanding several reforms and statements such as those associated with the strengthening of the Single Market, there is still considerable room for improvement in this area in Spain, as there is limited flexibility in some prices. Take for instance the issue of the Spanish energy prices. In essence, this dimension of our outcome (inflation persistence), which is brought into light by our PANIC analysis reinforces the previous results in this area.

A final exercise consists of a multivariate regression analysis aimed at determining the factors responsible for Spanish inflation. In our view, given the characteristics of the Spanish economy, all the signs from the multivariate analysis are plausible, in terms of the Phillips curve, the non-wage price pressure, the disinflationary competition and sectoral specialization patterns-given the problems and rigidities of the goods and labor markets in Spain. Finally, the negative sign of the coefficient on real GVA per capita growth does not support the validity of the Balassa-Samuelson effect.

The remainder of our article is structured as follows. Section 2 conducts a review to further contextualize our work in the related literature. Section 3 presents the PANIC approach. Section 4 makes a description of the inflation data employed and analyzes the choice of the break considered. Section 5 comments on the results obtained from the PANIC analysis and provides an alternative test of pairwise convergence. Section 6 carries out an analysis utilizing some additional variables other than inflation, also paying attention to CPI weightings and testing the BalassaSamuelson hypothesis. Finally, Sect. 7 concludes.

\footnotetext{
${ }^{6}$ Galí and López-Salido (2001), within the framework of the recent literature about the Phillips curvesee Galí and Gertler (1999)_, emphasize the role of wage frictions and the backward-looking component of inflation expectations. That second factor is also stressed by Fabiani et al. (2006). Restoy et al. (2005) point to the problem of the Spanish dual inflation. Likewise, they highlight the relevant role of wage indexation. Caraballo and Dabús (2013) and Caraballo and Usabiaga (2009a, b) present evidence for the presence of menu costs - or other nominal rigidities-in the determination of Spanish consumer and producer prices. The latter also focuses on the vulnerability of Spanish inflation to adverse oil shocks. Finally, we should underline that the labor reforms undertaken between 2010 and 2012 (Bentolila et al. 2012), which supposedly have decreased workers' and trade unions' bargaining power, might have affected those aforesaid labor variables (reducing wage indexation, removing, at least partially, the insider-outsider problem, etc.).
} 


\section{Literature review}

\subsection{Disinflation and inflation convergence: evidence and lessons for Latin America}

One geographic area that has long struggled to end high and chronic inflation is Latin America. Latin American countries have endured bouts of high inflation and hyperinflation in the recent past and some of them (mainly Venezuela and Argentina) are currently grappling with this scourge again. For the remaining countries, on a general basis inflation has come down from high numbers in the 70s, 80 s and 90 s to more moderate rates in the present decade. It is worth mentioning that, in addition to opening themselves up to trade, countries like Mexico, Chile, Peru, Colombia and Uruguay are known to have been quite successful in bringing to birth a full-fledged inflation-targeting regime. ${ }^{7}$ The inflation rates after the implementation of the new framework plummeted in all these economies. ${ }^{8}$ Additionally, to be sustainable, this monetary arrangement calls for the conduct of a more rigorous fiscal policy which may have also played some role in helping drive inflation down over time. ${ }^{9}$ It is important to mention that the evidence mostly points to the existence of a positive relation between the interplay of globalization and monetary policy, via the incentives that the former raises for central banks to behave prudently, and disinflation.

To our knowledge, the literature on the effects of the interaction of the aforementioned factors on inflation convergence within countries is fairly scant, especially in Latin America. Intuitively, a country's regions, subject to the same monetary policy and roughly similar structural reforms and fiscal policies, should in principle experience long-run inflation convergence (Yilmazkuday 2013). Moreover, if, as a consequence of a further step taken toward a deeper economic and monetary integration, some of these joint policies are carried out at a supranational level, while others are influenced or restricted by common rules set at the same level, a stronger sub-national inflation convergence is likely to occur, at least throughout the initial stages of the process.

From a policy-oriented perspective, we view this analysis as relevant since nonnegligible differences in real interest rates could arise within the country did regional inflation rates differ from each other, due for instance to distinct cyclical positions across these regions' economies, thereby perpetuating diverging economic performances at regional level. Besides, persistent differences in inflation might reflect permanent structural rigidities that prevent the regions hardest hit by shocks from adjusting swiftly.

\footnotetext{
7 Brazil is another inflation targeter in the region, but we have elected to leave it out of our comments as it is a relatively closed economy.

8 See Blake et al. (2015), for an application to Chile, Colombia, Mexico and Peru, and García-Solanes and Torrejón-Flores (2012), for the same countries plus Brazil.

9 To get a sense of how important fiscal discipline can be under an inflation-targeting regime, see Mishkin (2000), for a general application to a set of emerging-market economies, Blanchard (2005), on the Brazilian case, and Ramos-Francia and Torres (2005), with a focus on the Mexican case.
} 
Let us now pick two countries, Mexico and Peru, among the "globalizers" we just chose because of data and empirical evidence availability. In the case of the former, to the best of our knowledge, only studies on regional (relative) price convergence can be found. Sonora (2005) tests whether the PPP hypothesis holds across Mexico's main cities. His results show that there is relative price convergence in the long run. Furthermore, he also suggests that prices are relatively flexible, which runs counter to the slower long-run price convergence found for US and Canadian data. Gómez-Aguirre and Rodríguez-Chávez (2013a, b) also examine price convergence across the main Mexican cities by employing panel data unit root tests. Their findings in both papers coincide with Sonora's: absolute price parity holds in the long run. As far as inflation convergence is concerned, a quick inspection of Mexican provincial inflation rate data (Instituto Nacional de Estadística y Geografía) provides a clue as to whether there has been regional/ provincial inflation convergence over time. A simple sigma-convergence analysis leads us to think this has been the case. Mexico is a NAFTA member and is therefore relatively integrated by commercial and financial ties with the US and Canada, and with the rest of the world as well. This relevant economic integration, coupled with sound economic policies, in part due to the necessary consistency with the status of being a more open economy, may have contributed to this regional/ local inflation convergence coming about over time.

On the Peruvian economy, Winkelried and Gutiérrez (2012) show that the central bank of Peru, by having targeted Lima's inflation, has been in fact influencing the economy-wide inflation, ${ }^{10}$ which in the end constitutes an indication that regional inflation rates have converged over time. By means of a multivariate dynamic model of inflation comprising the main nine regions in the country, they conclude that the relative PPP holds among pairs of regional inflations. Again, Peru is an economy whose recent progress on the macroeconomic and institutional front has been remarkable. This virtuous cycle, in a way sparked by these aforementioned good policies, ${ }^{11}$ has materialized itself in considerable economic growth rates and low inflation. ${ }^{12}$ A steady convergence in regional inflation is an expected outcome given the policies put in place from the 90s onwards.

As may be seen, the Spanish case that we choose to analyze in this article can be generalized to other open economies, such as several in Latin America, to the extent that these latter economies share certain characteristics with the Spanish economy (degree of openness, central bank behavior, fiscal policy stance, etc.).

\footnotetext{
${ }^{10}$ As the authors themselves say, Peru is a heavily centralized country, as Lima concentrates about a third of the country's population and used to represent more than $70 \%$ of national expenditure.

11 Some economists assert that "good luck" seems to have played a greater role than good policies have in causing Peru's notable economic performance—see for example Mendoza (2013).

12 Although risks stemming from external shocks like the fall in commodity prices on international markets and the foreseeable US monetary policy tightening, along with the fact that Peru is still a partially dollarized economy, might threaten the hard-won macroeconomic stability—see for instance IMF (2015).
} 


\subsection{Disinflation and inflation convergence within a European context}

After the view of the processes of disinflation and convergence in inflation in Latin America, we are going to concentrate now on the Spanish case, logically placed within the euro area context. The process of Spanish disinflation in the past decades is well-known, and it has been widely studied using mainly the SVAR methodology — see the survey by Gómez and Usabiaga (2001).

As regards convergence, there exist several strands in the literature covering price level convergence, inflation convergence and inflation differentials. Although logically those literatures are closely related, each one of those research lines has some economic and econometric specific features. On the inflation rates and their convergence, main topic of our paper, there are more country-based case studies than region-based ones. For instance, there is a lot of literature on this topic for Western European countries. One can also find abundant literature on the euro area countries' inflation differentials—see de Haan (2010) for a survey as well as several ECB publications.

Although with slight caveats, related to the price indices, the time periods, or the countries considered, in general, for the euro area countries inflation convergence has been reported — see for instance Montuenga-Gómez (2002), Busetti et al. (2007) and Beck et al. (2009)—, mainly before the mid-90s. However, there still exist significant and persistent inflation differentials in the euro area (de Haan 2010), which even allow classifying countries under different categories or clusters-see for instance Montuenga-Gómez (2002) and Busetti et al. (2007).

Beck et al. (2009, p. 153), with the euro zone in mind, present the following classification of the potential underlying factors in inflation differentials-de Haan (2010) uses a roughly similar classification-: (1) differences between the actual positions of the economies within their business cycles, asymmetric shocks, and asymmetric effects of area-wide impulses such as monetary impulses, exchange rate movements or oil price changes. (2) The Balassa-Samuelson effect. (3) Inappropriate domestic policies or other unwarranted domestic developments such as misaligned fiscal policies, immoderate wage evolution, or other production input factor price developments. (4) Nominal wage and price rigidities. Beck et al. (2009) point out that the most worrisome factors are those of the two last types.

There is no clear consensus on the specific underlying sources of the inflation differentials among the euro area countries, although there may be a consensus about the fact that they are rooted on structural or institutional factors-see for instance Jaumotte and Morsy (2012) and Beck et al. (2009). In this respect, Jaumotte and Morsy (2012), for a panel of 10 euro area countries (period 1983-2007), conclude that in order to reduce the persistent inflation differentials the following labor elements have to be reformed: high employment protection, intermediate coordination of collective bargaining and high union density. In this line, de Haan (2010) highlights that most empirical research suggests that EMU has not spurred labor market reform. However, Beck et al. (2009) do not emphasize the labor factors for the regional euro area inflation differentials. In their opinion, those differentials are mainly accounted for by the costs of the non-wage input factors, the degree of competition and the economic structure of the regions. In other words, the 
observed long-run differences are chiefly caused by inefficiencies in factor markets and region-specific structural characteristics. They also remark that there is considerable heterogeneity in the economic structure of euro area regions such that even symmetric impulses-such as a monetary policy shock-can have heterogeneous effects.

From the analysis of the regional inflation rates of the euro area countries, Beck et al. (2009) state that national factors matter. Thus, the dispersion is higher among the regions of all the European countries analyzed (Austria, Finland, Germany, Italy, Norway and Spain) than among the regions of each country. In addition, differences are substantially more pronounced across regions than across country averages. These authors assert that the strong influence of the national factor very likely stems both from nationally conducted fiscal policy and nationally determined labor market institutions. In comparison to US regional inflation rates, the euro area regional rates show a slightly higher degree of dispersion and persistence. Using a factor model, Beck et al. (2009) find that the variation in euro area regional inflation rates is explained following these proportions: area-wide factors $50 \%$, national factors $32 \%$, regional elements $18 \%$ (Spain: national factors $26.8 \%$, regional factors $24.6 \%$ ). They come to the conclusion that the Spanish differential in this respect can probably be explained by the relatively high degree of independence that Spanish regions enjoy.

Several works highlight that the monetary policy followed by EMU could have generated convergence effects also at regional level, due to its effect on expectations and other factors. For instance, Beck et al. (2009) state that the area-wide monetary policy can considerably contribute to regional inflation stabilization even though it cannot take regional developments into account when making its decisions. Apart from Beck et al. (2009), other works also report regional inflation convergence. For instance, Busetti et al. (2006) conduct an analysis of the price level and the inflation rate for the monthly series of the CPI in 19 Italian regional capitals over the 1970-2003 period, concluding that the convergence process is stronger for the inflation rate. Gozgor (2013) also observes convergence in Turkish regional inflation rates (period 2004-2011).

Yilmazkuday (2013) tackles a more disaggregated analysis of regional inflation, in the line of the works related to the Balassa-Samuelson literature. He works with ten main CPI groups for each region, distinguishing between groups concentrated on tradable and non-tradable components (period 1994-2004). In this study a break in Turkish inflation is captured in 2002, and in 2001 for the cross-sectional standard deviation of regional inflation rates. This author distinguishes between a preinflation targeting period and an inflation targeting period (which coincides with a flexible exchange rate) starting from January 2002. As in our study, Pesaran (2007a)'s methodology is used, among other techniques-Arestis et al. (2014) also use that technique, but applied to countries' inflation. As acknowledged by Yilmazkuday (2013), the results of this work require further study since during the inflation targeting period the CPI groups with relatively tradable components have diverged from each other, while the non-tradable groups have converged to each other. Caraballo and Usabiaga (2009c) share some elements of the disaggregated study of Yilmazkuday (2013) in their analysis of Spanish and Andalusian inflation. 
Finally, in the present study we can state that when we disaggregate provincial CPIbased inflation rates into province-level inflation rates of the 12 COICOP groups of goods and services over the 1994-2015 period, we are able to uncover some interesting patterns. With the exception of the Communications group involving mainly non-tradables, all the other groups of goods and services appear to exhibit a high degree of convergence among pairs of inflation rates across provinces. This indicates that convergence in provincial inflation rates is widespread across groups of goods and services, irrespective of the tradables/non-tradables distinction.

It is well accepted that the Balassa-Samuelson effect fails to account for the euro area inflation dynamics-see ECB (2005), Rogers (2007) and Beck et al. (2009). The Spanish economy is not an exception in this regard, maybe because some of its assumptions do not hold in that economy; for instance features like a rather centralized wage determination, a low labor mobility, etc. (Jimeno and Bentolila 1998), run counter to its central assumptions. Juselius and Ordóñez (2009) point out that the potential Balassa-Samuelson effect has more influence over the high unemployment than over prices. Rabanal (2009) concludes that the BalassaSamuelson effect does not appear to be an important driver of the inflation differential Spain-EMU during the EMU period, although a gap in labor productivity between tradable and non-tradable sectors can be noted. In addition, Alberola and Marqués (2001) reject the Balassa-Samuelson hypothesis at Spanish regional level. Finally, in Beck et al. (2009) this theory is not supported for the Spanish regions. To sum up, there is overwhelming evidence against the relevance and explanatory power of that hypothesis for the Spanish economy. Our results do not support the Balassa-Samuelson hypothesis since there is not a significantly higher degree of convergence among pairs of provincial inflation rates for tradables, relative to non-tradables (of course bearing in mind the exception of the Communications sector). Likewise, our multivariate regression analysis provides evidence of a significantly negative impact of real GVA per capita growth on the inflation rate, which runs counter to the positive effect that would be predicted according to the Balassa-Samuelson hypothesis.

\section{PANIC approach}

Different from most second-generation panel unit root tests that only allow for weak forms of cross-sectional dependence (contemporaneous short-run cross-correlation), some panel unit root tests relying on linear factor models can enable stronger forms of cross-dependence such as cross-sectional cointegration. Among the panel procedures that use a factor structure are Moon and Perron (2004), Pesaran (2007b) and Bai and Ng (2004a, b, 2010). While Pesaran (2007b) just allows for one common factor, Moon and Perron (2004) and Bai and Ng (2004a, b, 2010) allow for multiple common factors. Nevertheless, only the panel tests of Bai and $\mathrm{Ng}$ (2004a, b, 2010) are sufficiently general to allow for cointegration across units, which entails that the observed series can include common stochastic trends. Actually, under this framework the observed series is broken down into a common and an idiosyncratic component, and if the latter component is found to be $I(0)$, the 
observed series and the common factor would be cointegrated. In that particular case of cross-cointegration, the tests of Pesaran (2007b) and Moon and Perron (2004) probably display size distortions, as the common trends may be confused with the common factors and thus taken away from the data in the defactoring process. Hence, the tests on the observed series seem to yield stationarity if the remaining idiosyncratic component is stationary, in spite of the presence of nonstationary common factors.

Let us model the observed data on inflation rates (denoted by $\pi_{i t}$ ) as the sum of a deterministic part, a common component and an idiosyncratic error term:

$$
\pi_{i t}=D_{i t}+\lambda_{i}^{\prime} F_{t}+e_{i t}
$$

where $\lambda_{i}$ is an $r \times 1$ vector of factor loadings, $F_{t}$ is an $r \times 1$ vector of common factors, and $e_{i t}$ is the idiosyncratic component. $D_{i t}$ can contain a constant and a linear trend. Since $\lambda_{i}$ and $F_{t}$ can only be estimated consistently when $e_{i t} \sim I(0)$, we estimate a model in first-differences like $\Delta \pi_{i t}=\lambda_{j}^{\prime} f_{t}+z_{i t}$, where $z_{i t}=\Delta e_{i t}$ and $f_{t}=\Delta F_{t} \cdot{ }^{13}$ We next use principal components to estimate the common factors $\left(\hat{f}_{t}\right)$, the corresponding factor loadings $\left(\hat{\lambda}_{i}\right)$ and the residuals $\left(\hat{z}_{i t}=\Delta \pi_{i t}-\hat{\lambda}_{i}^{\prime} \hat{f}_{t}\right)$, so that we preserve the order of integration of $F_{t}$ and $e_{i t}$. As in Bai and $\mathrm{Ng}$ (2002), we normalize $\pi_{i t}$ for each cross-section unit to have a unit variance. The common factors and the residuals are then obtained as follows: $\hat{F}_{t}=\sum_{s=2}^{t} \hat{f}_{s}$ and $\hat{e}_{i t}=\sum_{s=2}^{t} \hat{z}_{i s}$, which can be used to test for a unit root in the common and idiosyncratic components, respectively.

\subsection{Determining the number of common factors}

Prior to testing for a unit root in the common and idiosyncratic components, we make use of information criteria to set the number of common factors contained in the panels of inflation rate series. We do so with the $\mathrm{BIC}_{3}$ information criterion:

$$
\mathrm{BIC}_{3}(k)=\hat{\sigma}_{\mathrm{e}}^{2}(k)+k \hat{\sigma}_{\mathrm{e}}^{2}(k \max )\left(\frac{(N+T-k) \ln (N T)}{N T}\right)
$$

where $k$ is the number of factors included in the model, $\hat{\sigma}_{\mathrm{e}}^{2}(k)$ is the variance of the estimated idiosyncratic components, and $\hat{\sigma}_{\mathrm{e}}^{2}\left(k_{\max }\right)$ is the variance of the idiosyncratic components estimated with the maximum number of factors $\left(k_{\max }=5\right) .{ }^{14}$ The optimal number of common factors $(\hat{k})$ is chosen by applying $\arg \min _{0} \leq k \leq 5 \mathrm{BIC}_{3}(k)$. The $\mathrm{BIC}_{3}$ is elected over other alternatives (like the $\mathrm{IC}_{\mathrm{p}}$ information criteria) because for a general enough framework in which the idiosyncratic errors can be serially correlated and cross-correlated, the $\mathrm{BIC}_{3}$

\footnotetext{
13 This representation amounts to the factor model with a constant. For the representation in the case of a specification with a trend, we refer to Bai and $\mathrm{Ng}$ (2004a, p. 1137).

14 The second argument in the loss function stands for the penalty for overfitting, which aims to correct for the fact that models with a larger number of factors can at least fit as good as models with fewer common factors, but efficiency is reduced with the estimation of more factor loading parameters (Bai and $\mathrm{Ng}$ 2002).
} 
criterion shows very good properties (Bai and $\mathrm{Ng}$ 2002). Likewise, Moon and Perron (2007) point out that the $\mathrm{BIC}_{3}$ criterion performs better in selecting the number of factors when $\min (N, T)$ is small.

\subsection{Analysis of the idiosyncratic component}

Before digging deeper into the methodology behind the PANIC approach, it is worth noting that the unit root tests of Bai and $\mathrm{Ng}$ (2004a, 2010) and the stationarity tests of Bai and $\mathrm{Ng}$ (2004b) have been combined, always within the PANIC framework, as dictated in the original articles. ${ }^{15}$ Bai and $\mathrm{Ng}$ (2004a) estimate standard Augmented Dickey-Fuller (ADF) specifications for a unit root in the idiosyncratic components:

$$
\Delta \hat{e}_{i t}=\delta_{i, 0} \hat{e}_{i, t-1}+\sum_{j=1}^{p_{i}} \delta_{i, j} \Delta \hat{e}_{i, t-j}+u_{i t}
$$

The ADF $t$-statistic for testing $\delta_{i, 0}=0$ is denoted by $\operatorname{ADF}_{\hat{e}}^{c}(i)$ or $\operatorname{ADF}_{\hat{e}}^{\tau}(i)$ for the cases of only a constant and a constant and a linear trend in specification (1), respectively. ${ }^{16}$ To raise statistical power, Bai and $\mathrm{Ng}$ (2004a) deploy pooled statistics based on the Fisher-type inverse Chi square tests of Maddala and Wu (1999) and Choi (2001). Letting $\pi_{\hat{e}}^{c}(i)$ be the $p$-value associated with $\operatorname{ADF}_{\hat{e}}^{c}(i)$, the pooled statistics are constructed as follows ${ }^{17}$ :

$$
\begin{gathered}
P_{\hat{e}}^{c}=-2 \sum_{i=1}^{N} \log \pi_{\hat{e}}^{c}(i) \stackrel{d}{\longrightarrow} x_{(2 N)}^{2} \quad \text { for } N \text { fixed, } \quad T \rightarrow \infty \\
Z_{\hat{e}}^{c}=\frac{-\sum_{i=1}^{N} \log \pi_{\hat{e}}^{c}(i)-N}{\sqrt{N}} \stackrel{d}{\longrightarrow} N(0,1) \text { for } N, \quad T \rightarrow \infty
\end{gathered}
$$

We also employ the two Moon and Perron (2004) type pooled tests utilizing the PANIC residuals to estimate a bias-corrected pooled PANIC autoregressive estimator, and a panel version of the Sargan-Bhargava (1983) statistic using the sample moments of the residuals without the need to estimate the pooled autoregressive coefficients. A great advantage of the PANIC pooled statistics of

\footnotetext{
15 The use of unit root statistics (for the case of testing the unit root null hypothesis) along with stationarity statistics (for the case of testing the stationarity null hypothesis) allows us to carry out a confirmatory analysis of the stochastic properties of the inflation rate series. See more details in Shin and Snell (2006, p. 136).

16 The asymptotic distribution of $\operatorname{ADF}_{\hat{e}}^{c}(i)$ is the same as the Dickey-Fuller distribution for the case of no constant, while that of $\operatorname{ADF}_{\hat{e}}^{\tau}(i)$ is proportional to the reciprocal of a Brownian bridge.

17 The same holds for the case of a trend, where $\pi_{\hat{e}}^{\tau}(i)$ is the $p$-value associated with $\operatorname{ADF}_{\hat{e}}^{\tau}(i)$. The pooled statistics for the trend specification are denoted as $P_{\hat{e}}^{\tau}$ and $Z_{\hat{e}}^{\tau}$. Note that we do not pool individual unit root tests for the observed series, since under a factor structure the limiting distribution of the test would contain terms that are common across units. However, "pooling of tests for $\hat{e}_{i t}$ is asymptotically valid under the more plausible assumption that $\hat{e}_{i t}$ is independent across $i$ " (Bai and Ng 2004a, p. 1140).
} 
Bai and $\mathrm{Ng}$ (2010) is that there is no need for least squares linear detrending that could give rise to a fall in statistical power.

\subsection{Analysis of the common component}

An ADF test is used to test for non-stationarity in the common factor. When the panel only has one common factor, as it is our case, we estimate an ADF specification for $\widehat{F}_{t}$ with the same deterministic components as in model (1):

$$
\Delta \hat{F}_{t}=D_{t}+\gamma_{0} \hat{F}_{t-1}+\sum_{j=1}^{p} \gamma_{j} \Delta \hat{F}_{t-j}+v_{t}
$$

The corresponding ADF $t$-statistics are denoted by $\mathrm{ADF}_{\hat{F}}^{c}$ and $\mathrm{ADF}_{\hat{F}}^{\tau}$ and follow the limiting distribution of the Dickey and Fuller (1979) test for the specifications with only a constant, and a constant and a trend, respectively.

\subsection{Stationarity tests for the common and idiosyncratic components}

As noted above, the stationarity test of Kwiatkowski et al. (1992, KPSS) is used and applied to both the common and idiosyncratic components following Bai and $\mathrm{Ng}$ (2004b). The univariate KPSS tests for the idiosyncratic components are denoted by $S_{\hat{e}}^{c}(i)$ and $S_{\hat{e}_{0}}^{\tau}(i)$ depending on whether trends appear or not in the specification, and the tests for the common factors are $S_{\hat{F}}^{c}$ and $S_{\hat{F}}^{\tau}$. The limiting distribution of $S_{\hat{F}}^{c}$ and $S_{\hat{F}}^{\tau}$ are those derived by KPSS for the cases of a constant, and a constant and a linear trend, respectively. However, the limiting distribution for testing $\hat{e}_{i t}$ depends on whether $\hat{F}_{t}$ is $I(0)$ or $I(1)$. If all factors are $I(0), S_{\hat{e}_{0}}^{c}(i)$ and $S_{\hat{e}_{0}}^{\tau}(i)$ follow the distribution of the KPSS tests for the cases of a constant, and a constant and a trend, respectively. But if the factor is $I(1)$, as it is our case, stationarity in the idiosyncratic component implies cointegration between the observed series and the $I(1)$ common factor. In that case, we have to employ univariate cointegration tests denoted by $S_{\hat{e}_{1}}^{c}(i)$ and $S_{\hat{e}_{1}}^{\tau}(i)$, which have the limiting distribution of the cointegration test of Shin (1994).

With respect to the computation of pooled statistics, when the common factors are stationary, the $p$-values associated with the univariate KPSS tests for the idiosyncratic components can be used to compute the pooled tests of Maddala and $\mathrm{Wu}$ (1999) and Choi (2001). Otherwise, pooling is not valid since the nonstationarity of the common factors is transmitted to the residuals under the null hypothesis of stationarity because it does not fade away even asymptotically. ${ }^{18}$

\footnotetext{
18 This analysis is conducted with MATLAB routines kindly provided by Serena $\mathrm{Ng}$ at http://www. columbia.edu/ sn2294/papers/panic.zip.
} 


\section{Inflation data and the timing of the break}

\subsection{Data description}

The main data we deploy in this article are CPI data, ${ }^{19}$ spanning from 1955.1 until 2014.4 at a monthly frequency, and they are sourced from INE (Instituto Nacional de Estadística). We avail ourselves of year-on-year numbers so as to avoid the seasonality problem. The data correspond to provincial capitals (up to 1992) and to provinces themselves thereafter. Connecting both kinds of series, without manipulating them, proves unproblematic. We have only engaged in two very specific manipulations of our inflation series in order to correct for two anomalous figures related to the province of Zamora, in 1960.1 and $1961.1 .^{20}$ In spite of having access to previous years, we have decided to stick to 1955 as the first year of our study mainly for three reasons: (1) because we would not like to go too far back in time, since our analysis neither aims to adopt an economic history approach nor to deal with episodes too far back in history. (2) Because data might cease to be statistically trustworthy as we move backwards in time, this trust being a fundamental factor for the econometric analysis conducted. (3) Because for additional assessments we make use of some other series, in addition to inflation, which mostly start after 1955.

Our work's basic data (inflation rate) is a panel made up of $50(N$, provinces) by 712 ( $T$, months). Nevertheless, for our purposes, the aforesaid panel is split into two different sub-samples. Indeed, in what follows, our article attempts to clarify whether the behavior of the provincial inflation rate varies between sub-periods. But before turning to the PANIC analysis, we next try to determine through econometric techniques where the break is located, as a better alternative to exogenously imposing it.

\subsection{Determination of the endogenous break in inflation}

In order to determine the most likely break in the provincial inflation rate series, we need to find the most likely common structural shift that is affecting all the series simultaneously. ${ }^{21}$ The avenue we take for that is to test for structural instability in the common stochastic trend that is driving all province-specific inflation rate series over the whole period. To identify the break location we follow the procedure proposed by Lee and Strazicich (2003). Unlike the Lumsdaine and Papell (1997) unit root test which is derived assuming no breaks under the null hypothesis, the unit root test of LS allows for breaks under both the null and alternative hypotheses. As pointed out by LS, rejection of the null with the Lumsdaine and Papell (1997) test only indicates rejection of a unit root without breaks, whereas the alternative does

\footnotetext{
19 Unfortunately, the existing data do not enable us to conduct an analysis of production prices akin to the one implemented in this work.

${ }^{20}$ Given that they were a very low value and a very high one, respectively, we have opted to give it the second lowest value and the second highest value, respectively, as they were more suitable altogether.

21 Romero-Ávila and Usabiaga (2009) study the breaks for OECD countries' national inflation series.
} 
not necessarily imply stationarity around a shifting trend. Using the Lagrange Multiplier (LM) score principle, LS estimate the following regression:

$$
\Delta \pi_{t}=\delta^{\prime} \Delta Z_{t}+\phi \tilde{S}_{t-1}+\sum_{1}^{k} \gamma_{i} \Delta \tilde{S}_{t-i}+\varepsilon_{t}
$$

where $\tilde{S}_{t-1}$ represents the detrended series such that $\tilde{S}_{t}=\pi_{t}-\tilde{\psi}_{X}-Z_{t} \tilde{\delta}$, for $t=2$ $\ldots T . \tilde{\delta}$ is a vector of coefficients estimated from the regression of $\Delta \pi_{t}$ on $\Delta Z_{t}$ and $\tilde{\psi}_{\mathrm{X}}=\pi_{1}-Z_{1} \tilde{\delta}$, where $\pi_{1}$ and $Z_{1}$ are the first observations of $\pi_{t}$ and $Z_{t}$ respectively, and $Z_{t}$ is a vector of exogenous variables defined by the data generation process of the inflation rate series. The crash model allows for one shift in the intercept such that $Z_{t}=\left[1, t, \mathrm{DU}_{1 t}\right]^{\prime} .^{22}$ The mixed change model allows for one change in level and slope, as given by $Z_{t}=\left[1, t, \mathrm{DU}_{1 t}, \mathrm{DT}_{1 t}\right]^{\prime}$.

The unit root null hypothesis is given by $\phi=0$ versus the alternative that $\phi<0$, and the LM $t$-statistic is defined by $\tilde{\tau}$ ( $t$-statistic testing the null hypothesis that $\phi=0)$. The minimum LM unit root $t$-statistic determines the endogenous location of the break $\left(\lambda=T_{\mathrm{B}} / T\right)$ by using a grid search over all possible break points such that $\operatorname{LM}_{\tau}=\inf _{\lambda} \tilde{\tau}(\lambda)$. To correct for serial correlation, we control for a sufficiently large number of augmentation terms $(k)$ by employing the general to specific approach proposed by $\mathrm{Ng}$ and Perron (1995), setting $k_{\max }=12 .^{23}$

For the crash model the mean shift is located at July 1978, whereas for the mixed change model the shift in mean and slope appears located at April 1979. Given the non-trending behavior exhibited by the inflation rate, we base our conclusions on the crash model which points to the existence of a mean shift at July 1978. The cross-province mean inflation rate for the first regime equals $9.4 \%$, whereas it equals $5.8 \%$ for the post-break regime, implying a clear downward shift in the mean inflation rate after the break took place. In addition, it is interesting to point out that the value of the LM unit root test of LS for the crash and mixed change models is -2.155 and -2.795 , respectively, both values well below (in absolute terms) the respective $10 \%$ critical values $(-3.504$ and -4.989$)$. This indicates the existence of a unit root in the common factor for the whole period after accounting for one structural break in the mean (and slope) of the series.

For robustness purposes, we also applied the generalized least squares (GLS)based unit root tests allowing for one break under both the null and alternative hypotheses proposed by Carrión-i-Silvestre et al. (2009). These tests include the class of modified tests ( $M$ tests), originally proposed by Stock (1999), and later extended by Perron and Ng (1996) and Ng and Perron (2001). The latter apply local-

\footnotetext{
22 Our model allows for a structural break under the null and the alternative, thus controlling for a change in level under the alternative and for a one-period jump under the null hypothesis.

23 To sum up, this approach presents several methodological advantages. First, the distribution of the $t$ statistic does not depend on nuisance parameters on the break location under the null. Second, the minimum LM $t$-statistic allows for a break under the null and alternative, which avoids the possibility of spurious rejections caused by size distortions (Lee and Strazicich 2001). Third, the location of the break and the degree of augmentation are endogenously and jointly determined prior to the computation of the LM unit root $t$-statistic. This analysis is conducted with GAUSS routines kindly provided by Junsoo Lee at the University of Alabama.
} 
to-unity GLS detrending instead of ordinary least squares (OLS) when estimating the deterministic components of an ADF regression (see Elliot et al. 1996) so that important gains in statistical power can be achieved. More specifically, we employ the $\mathrm{ADF}^{\mathrm{GLS}}$ test first proposed by Elliot et al. (1996), which is the $t$-statistic for testing the existence of a unit root with a specification where the underlying series is detrended with GLS prior to estimation by OLS. The $M^{\mathrm{GLS}}$-class of tests includes $\mathrm{MZ}_{\alpha}^{\mathrm{GLS}}$ and $\mathrm{MZ}_{t}^{\mathrm{GLS}}$ which are modified versions of the $Z_{\alpha}$ and $Z_{t}$ Phillips and Perron (1988) tests, MSB ${ }^{\mathrm{GLS}}$ which is a modified version of the Sargan and Bhargava (1983) test, the feasible point optimal test $\left(P_{\mathrm{T}}^{\mathrm{GLS}}\right)$ and the modified feasible point optimal test $\left(\mathrm{MP}_{\mathrm{T}}^{\mathrm{GLS}}\right){ }^{24}$ In this case, the break is located at August 1977, which is very close to the break date identified with the LS procedure. Since a visual inspection of Fig. 1 appears to favor a major downward shift in mean inflation in the middle of 1978, we stick to the result obtained from the application of LS methods. Still, it is reassuring that both methods render fairly similar results. Not surprisingly either, none of the GLS-based unit root tests is able to reject the unit root null hypothesis at conventional significance levels, ${ }^{25}$ thus supporting the non-stationarity of the common factor.

Our initial working hypothesis, which turns out to be confirmed throughout our analyses, is that from the break identified (1978.7) up to the present day a number of relevant economic, political and institutional changes, both at the national and international levels, have necessarily left their imprints on the inflation rate, among other variables. This changing pattern is intended to be captured, in a first step, via PANIC, and in a second step, via other convergence assessments.

The break identified can be largely thought of as a turning point in Spanish economic policy relative to Franco's dictatorial regime, leading to a period of a high reformist vigor brought about by the new democratic period that encompassed almost every economic area, both within the country itself and further afield, spurred by the firm intention of Spain to access to the European core. As regards Spanish internal policy, which has been progressively constrained by the European integration process, after the Pactos de la Moncloa (1977) - a battery of urgent policy measures in response to the peak in inflation-, one of the first measures taken was the adoption of the medium-term economic program 1983-1986 (updated twice afterwards). In this program, on the one hand, some adjustment policies were put into place with the aim of correcting the main macroeconomic imbalances, and, on the other hand, several structural reforms were fostered in order to better articulate the productive fabric of the country and enhance the efficient functioning

\footnotetext{
${ }^{24}$ For these tests to exhibit good size properties, it is crucial to select the appropriate lag truncation $(k)$ of the ADF specification. For that purpose, $\mathrm{Ng}$ and Perron (2001) develop the modified Akaike information criterion which aims at selecting a relatively long lag-length in the presence of a large negative moving average root (thus preventing size distortions) and a short lag-length when that root is not present (thus avoiding unnecessary loss of power). In our application, we take a maximum lag truncation of 12 . This analysis is conducted with GAUSS routines kindly provided by Pierre Perron at http://people.bu.edu/ perron/code/Replication-codes-ET-2009.zip.

25 Detailed results are available from the authors upon request.
} 


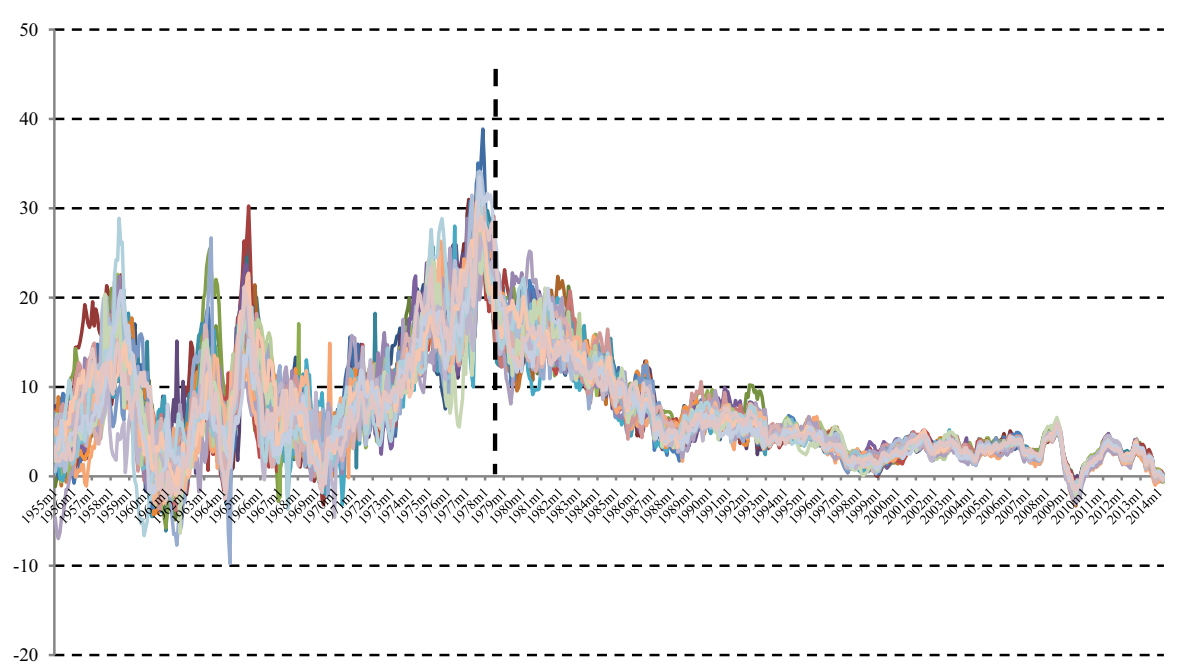

Fig. 1 Evolution of Spanish provincial inflation rates. Inter-annual data. 1955.1-2014.4

of the markets. ${ }^{26}$ It is also indisputable that the initiatives in favor of the European integration, and the legislative alignment that ensued from that, were crucial during those years which ended with Spain entering the European Economic Community (EEC) on January the 1st 1986. Within this process, the Maastricht Treaty called for central banks' independence of those countries aiming to join the Single Currency, which in the case of Spain led to the approval of the Law of Autonomy of the Bank of Spain (Law 13/1994). In the context of EMU, an inter-annual inflation target around $2 \%$ was established. $^{27}$

In case the justification of the timing of the break, based on institutional, political and economic grounds, was deemed insufficient, Fig. 1 plots the evolution of the provincial inflation rates for both periods analyzed. Even at first glance, it is easily observable that the nature of the series appears to have undergone a transformation between periods. Apart from a lower average inflation in the second period, ${ }^{28}$ even in those months in which inflation is at similar levels across both periods, a lower dispersion for the second one is perceived.

\footnotetext{
${ }^{26}$ On the adjustment measures, in addition to a strong commitment to income policies, great importance was placed on a restrictive monetary policy stance and on fighting inflation. This economic strategy was generally perceived to be the appropriate one at that time, following the second oil shock. As for the structural reform package, during those years a multitude of measures were conducted, like the industrial and energy restructuring, transformation of public enterprises, etc. We should also remember that the Spanish labor market approached the way a genuine market is supposed to function essentially from the break proposed onwards, right after trade unions were legalized in 1977, and the emergence of Workers' Statute in 1980.

27 On the European integration process, from an economic perspective, see for example Baldwin and Wyplosz (2013). From a regional point of view, see for example Cuadrado-Roura and Parellada (2002), Fingleton (2003) and Maza and Villaverde (2011).

${ }^{28}$ It should be remembered that there exists a strand of literature on the positive relation between average inflation and relative price variability (RPV)—see for instance Debelle and Lamont (1997).
} 


\section{Analysis of the PANIC results}

\subsection{Analysis of cross-sectional dependence}

Before we implement the PANIC analysis, two cross-dependence tests are applied to ascertain the likely existence of cross-correlation in inflation innovations for the two panels of inflation rate series under scrutiny. These tests are those put forward by Breusch and Pagan (1980) and Pesaran (2004). Pesaran's test rests on the average of pair-wise correlation coefficients $\left(\hat{\rho}_{i j}\right)$ of OLS residuals derived from standard ADF regressions for each individual. The order of the autoregressive model is selected using the $t$-sig criterion in $\mathrm{Ng}$ and Perron (1995), with the maximum number of lags set at $p=4(T / 100)^{1 / 4}$. This test adopts the form $\mathrm{CD}=\sqrt{2 T /(N(N-1))}\left(\sum_{i=1}^{N-1} \sum_{j=i+1}^{N} \hat{\rho}_{i j}\right) \stackrel{d}{\longrightarrow} N(0,1)$. The CD statistic tests the null hypothesis of cross-sectional independence, is distributed as a two-tailed standard normal distribution and exhibits good finite-sample properties. Moreover, Breusch and Pagan (1980) test the null hypothesis of cross-sectionally independent errors via the following LM statistic: $\left.\mathrm{CD}_{\operatorname{lm}}=T \sum_{i=1}^{N-1} \sum_{j=i+1}^{N} \hat{\rho}_{i j}^{2} \stackrel{d}{\longrightarrow} x_{N(N-1) / 2}^{2}\right)$. Even though throughout the analysis all the outcomes for the specification both with and without trends are computed, as inflation is often portrayed as a variable of the second type, we concentrate on the evidence obtained for the specification with no trends. ${ }^{29}$ For the two panels we are able to reject the null hypothesis of crosssectionally independent errors at the $1 \%$ level of significance with both the CD test and the Breusch and Pagan LM test (Table 1). This in turn supports the use of PANIC that allows for cross-sectional dependence so that large size distortions in the tests are avoided—see O'Connell (1998), Maddala and Wu (1999) and Banerjee et al. (2005).

\subsubsection{Optimal number of common factors}

Before testing for a unit root in the idiosyncratic series and common factors in which the inflation rate series forming the two panels are broken down, the common factors are estimated through principal components and the number of factors present in the two panels investigated is then selected. Table 2 displays the results from the application of the $\mathrm{BIC}_{3}$ criterion to the two panels of inflation series. This criterion picks one common factor for the two panels. Since Bai and Ng (2002) provided evidence that the $\mathrm{BIC}_{3}$ criterion performed remarkably well in the presence of cross-correlations and Gengenbach et al. (2010, p. 134) offered simulation evidence of the superior performance of the $\mathrm{BIC}_{3}$ criterion for short$N$ panels, and given the difficulty in establishing the number of common factors in panels with relatively short $N$, we will undertake the decomposition of the inflation rate series as if there existed one common factor, as specified by the $\mathrm{BIC}_{3}$ criterion.

\footnotetext{
29 As will become apparent below, the main results are fairly robust to the inclusion of a linear trend in the specification.
} 
Table 1 Cross-sectional dependence analysis

\begin{tabular}{llllll}
\hline & \multicolumn{3}{l}{ No trend specification } & & \multicolumn{2}{l}{ Trend specification } \\
\cline { 2 - 3 } \cline { 5 - 6 } & CPI. 50 provinces & CPI. 50 provinces & & CPI. 50 provinces & CPI. 50 provinces \\
& $1955.1-1978.6$ & $1978.7-2014.4$ & & $1955.1-1978.6$ & $1978.7-2014.4$ \\
\hline LM test & $491.383^{\mathrm{a}}$ & $2383.475^{\mathrm{a}}$ & & $488.076^{\mathrm{a}}$ & $2390.468^{\mathrm{a}}$ \\
CD test & $152.845^{\mathrm{a}}$ & $338.290^{\mathrm{a}}$ & & $152.327^{\mathrm{a}}$ & $338.767^{\mathrm{a}}$ \\
\hline
\end{tabular}

The CD-statistic and the LM-statistic test for the null of cross-sectional independence. The CD-statistic is distributed as a two-tailed standard normal distribution and the LM-statistic as a $\chi_{N(N-1) / 2}^{2}$ distribution

${ }^{\text {a }}$ Implies rejection of the null hypothesis at the $1 \%$ significance level

Table $2 \quad \mathrm{BIC}_{3}(k)$ information criterion

\begin{tabular}{lll}
\hline Number of factors $(k)$ & $\begin{array}{l}\text { CPI. 50 provinces } \\
1955.1-1978.6\end{array}$ & $\begin{array}{l}\text { CPI. 50 provinces } \\
1978.7-2014.4\end{array}$ \\
\hline 0 & 3.1637 & 0.4657 \\
1 & $2.5974^{\mathrm{a}}$ & $0.2857^{\mathrm{a}}$ \\
2 & 2.8457 & 0.3059 \\
3 & 3.1098 & 0.3279 \\
4 & 3.3886 & 0.3515 \\
5 & 3.6732 & 0.3781 \\
\hline
\end{tabular}

${ }^{a}$ Represents the lowest value of the information criteria. See the text for the equation associated with the information criterion

\subsection{PANIC analysis of the panel of CPI-based inflation rates for the Spanish provinces}

\subsubsection{First period results}

Table 3 presents the results of the univariate ADF and KPSS tests applied to the idiosyncratic series, the respective univariate tests for the common factor as well as the pooled statistics of Bai and $\mathrm{Ng}$ (2004a, 2010) for the panel of CPI-based inflation rate series for the 50 Spanish provinces over the period 1955.1-1978.6. The aim is to determine the source of non-stationarity in Spanish provincial inflation, i.e., whether the common and/or idiosyncratic series are non-stationary. In this case, the $\mathrm{BIC}_{3}$ procedure selected only one common factor.

Furthermore, as the univariate statistics applied to the common factor yield unclear evidence as to whether the common component is stationary or not (since the $\operatorname{ADF}_{\hat{F}}^{c}$ and $\operatorname{ADF}_{\hat{F}}^{\tau}$ statistics favor the stationarity hypothesis, whilst the $\operatorname{KPSS}_{\hat{F}}^{c}$ and $\operatorname{KPSS}_{\hat{F}}^{\tau}$ statistics lend support to the unit root hypothesis), we apply the IPC $1, \mathrm{IPC}_{2}$ and IPC information criteria of Bai (2004) as an alternative and more reliable methodology to determine the number of non-stationary common factors in the panel (setting the 
Table 3 PANIC analysis of CPI inflation. Spanish provinces. 1955.1-1978.6

\begin{tabular}{|c|c|c|c|c|c|c|c|c|}
\hline & \multicolumn{3}{|c|}{ No trend specification } & \multicolumn{5}{|c|}{ Trend specification } \\
\hline & $k$ & $\operatorname{ADF}_{\hat{e}}^{c}(i)$ & $S_{\hat{e}_{1}}^{c}(i)$ & $k$ & $\operatorname{ADF}_{\hat{e}}^{\tau}(i)$ & $S_{\hat{e}_{1}}^{\tau}(i)$ & $\frac{\sigma\left(\Delta \hat{e}_{i t}\right)}{\sigma\left(\Delta \pi_{i t}\right)}$ & $\frac{\sigma\left(\lambda_{i}^{\prime} F_{t}\right)}{\sigma\left(\hat{e}_{i t}\right)}$ \\
\hline Álava & 4 & $-3.969 * * *$ & 0.103 & 0 & $-3.990 * * *$ & 0.092 & 0.713 & 1.808 \\
\hline Albacete & 0 & $-4.315 * * *$ & $0.282 *$ & 0 & $-4.611 * * *$ & $0.110^{*}$ & 0.621 & 2.513 \\
\hline Alicante & 5 & $-4.327 * * *$ & 0.099 & 2 & $-4.582 * * *$ & 0.067 & 0.566 & 2.728 \\
\hline Almería & 0 & $-3.904 * * *$ & 0.056 & 0 & $-4.115^{* * *}$ & 0.056 & 0.604 & 2.299 \\
\hline Asturias & 0 & $-3.997 * * *$ & 0.072 & 0 & $-4.182 * * *$ & 0.068 & 0.704 & 2.018 \\
\hline Ávila & 0 & $-3.956 * * *$ & 0.102 & 0 & $-4.360 * * *$ & $0.101^{*}$ & 0.713 & 2.020 \\
\hline Badajoz & 8 & $-4.871 * * *$ & 0.053 & 0 & $-4.879 * * *$ & 0.052 & 0.579 & 3.554 \\
\hline Balears, Illes & 5 & $-3.026 * * *$ & $0.386^{* *}$ & 5 & $-2.917 * *$ & $0.190 * * *$ & 0.814 & 1.452 \\
\hline Barcelona & 0 & $-3.631 * * *$ & 0.092 & 0 & $-3.801 * * *$ & 0.085 & 0.773 & 2.223 \\
\hline Bizkaia & 1 & $-4.503 * * *$ & 0.187 & 1 & $-5.116^{* * * *}$ & 0.072 & 0.734 & 2.348 \\
\hline Burgos & 1 & $-2.855 * * *$ & 0.199 & 1 & $-3.317 * * *$ & 0.047 & 0.790 & 2.568 \\
\hline Cáceres & 5 & $-4.361 * * *$ & $0.284^{*}$ & 5 & $-4.368 * * *$ & 0.039 & 0.713 & 2.504 \\
\hline Cádiz & 2 & $-4.048 * * *$ & 0.100 & 2 & $-4.089 * * *$ & 0.077 & 0.621 & 2.501 \\
\hline Cantabria & 0 & $-4.841 * * *$ & 0.113 & 0 & $-4.861 * * *$ & 0.065 & 0.796 & 1.747 \\
\hline Castellón & 2 & $-3.493 * * *$ & $0.403 * *$ & 2 & $-3.781 * * *$ & $0.100 *$ & 0.647 & 1.758 \\
\hline Ciudad Real & 0 & $-3.315 * * *$ & 0.226 & 0 & $-3.823 * * *$ & 0.064 & 0.793 & 1.429 \\
\hline Córdoba & 0 & $-2.263 * *$ & $0.245^{*}$ & 0 & $-3.055^{* *}$ & 0.062 & 0.481 & 2.678 \\
\hline Coruña, A & 7 & $-3.194 * * *$ & $0.601 * * *$ & 7 & $-3.345^{* * *}$ & $0.194 * * *$ & 0.679 & 2.894 \\
\hline Cuenca & 3 & $-3.709 * * *$ & 0.193 & 2 & $-4.115^{* * *}$ & $0.106^{*}$ & 0.476 & 2.903 \\
\hline Gipuzkoa & 6 & $-4.536 * * *$ & 0.171 & 6 & -4.670 *** & 0.043 & 0.642 & 2.732 \\
\hline Girona & 1 & $-3.995 * * *$ & 0.228 & 1 & $-4.087 * * *$ & 0.071 & 0.826 & 2.256 \\
\hline Granada & 0 & $-4.153 * * *$ & 0.117 & 0 & $-4.306 * * *$ & 0.092 & 0.616 & 2.984 \\
\hline Guadalajara & 1 & $-4.610 * * *$ & 0.073 & 1 & $-4.615^{* * *}$ & 0.056 & 0.699 & 2.496 \\
\hline Huelva & 0 & $-4.262 * * *$ & 0.107 & 2 & $-4.252 * * *$ & 0.063 & 0.692 & 2.854 \\
\hline Huesca & 4 & $-3.838 * * *$ & 0.216 & 4 & $-4.414 * * *$ & $0.114 *$ & 0.689 & 2.441 \\
\hline Jaén & 0 & $-4.883 * * *$ & 0.068 & 0 & $-4.876^{* * *}$ & 0.054 & 0.639 & 2.371 \\
\hline León & 2 & $-5.574 * * *$ & 0.142 & 2 & $-5.555^{* * *}$ & 0.052 & 0.583 & 2.646 \\
\hline Lleida & 0 & $-3.462^{* * * *}$ & 0.134 & 0 & $-3.565^{* * *}$ & 0.068 & 0.755 & 2.075 \\
\hline Lugo & 0 & $-4.357 * * *$ & 0.043 & 0 & $-4.586^{* * * *}$ & 0.027 & 0.706 & 2.334 \\
\hline Madrid & 1 & $-3.878 * * *$ & $0.467 * *$ & 1 & $-4.187 * * *$ & $0.209 * * *$ & 0.545 & 2.426 \\
\hline Málaga & 0 & $-4.878 * * *$ & $0.276^{*}$ & 0 & $-4.877 * * *$ & 0.061 & 0.642 & 2.531 \\
\hline Murcia & 3 & $-3.824 * * *$ & 0.051 & 0 & $-4.072 * * *$ & 0.037 & 0.478 & 3.477 \\
\hline Navarra & 0 & $-3.068 * * *$ & 0.073 & 0 & $-3.605^{* * *}$ & 0.035 & 0.659 & 2.131 \\
\hline Ourense & 5 & $-5.854 * * *$ & 0.039 & 5 & $-5.858 * * *$ & 0.025 & 0.745 & 2.371 \\
\hline Palencia & 0 & $-4.587 * * *$ & 0.056 & 0 & $-4.587 * * *$ & 0.056 & 0.581 & 3.382 \\
\hline Palmas, Las & 3 & $-2.388^{* *}$ & $0.755^{* * *}$ & 3 & $-3.459 * * *$ & 0.072 & 0.879 & 1.259 \\
\hline Pontevedra & 2 & $-3.528 * * *$ & $0.421 * *$ & 2 & $-4.335^{* * * *}$ & 0.026 & 0.742 & 2.182 \\
\hline Rioja, La & 8 & $-3.044 * * *$ & $0.262 *$ & 5 & $-3.015^{* *}$ & $0.121 *$ & 0.713 & 1.947 \\
\hline Salamanca & 0 & $-4.158 * * *$ & 0.079 & 0 & $-4.174 * * *$ & 0.081 & 0.684 & 1.924 \\
\hline
\end{tabular}


Table 3 continued

\begin{tabular}{|c|c|c|c|c|c|c|c|c|c|}
\hline & \multicolumn{4}{|c|}{ No trend specification } & \multicolumn{5}{|c|}{ Trend specification } \\
\hline & $k$ & \multicolumn{2}{|c|}{$\operatorname{ADF}_{\hat{e}}^{c}(i)$} & $S_{\hat{e}_{1}}^{c}(i)$ & $k$ & $\operatorname{ADF}_{\hat{e}}^{\tau}(i)$ & $S_{\hat{e}_{1}}^{\tau}(i)$ & $\frac{\sigma\left(\Delta \hat{e}_{i t}\right)}{\sigma\left(\Delta \pi_{i t}\right)}$ & $\frac{\sigma\left(\lambda_{i}^{\prime} F_{t}\right)}{\sigma\left(\hat{e}_{i t}\right)}$ \\
\hline $\begin{array}{l}\text { Santa Cruz } \\
\text { de } \\
\text { Tenerife }\end{array}$ & 2 & \multicolumn{2}{|c|}{$-3.187 * * *$} & $0.475 * *$ & 2 & $-4.164 * * *$ & 0.057 & 0.947 & 0.607 \\
\hline Segovia & 0 & \multicolumn{2}{|c|}{$-4.200 * * *$} & 0.069 & 0 & $-4.299 * * *$ & 0.052 & 0.641 & 3.076 \\
\hline Sevilla & 0 & \multicolumn{2}{|c|}{$-4.951 * * *$} & 0.182 & 0 & $-4.991 * * *$ & 0.066 & 0.632 & 2.607 \\
\hline Soria & 3 & \multicolumn{2}{|c|}{$-2.820 * * *$} & 0.115 & 3 & $-2.792 * *$ & $0.105^{*}$ & 0.725 & 2.173 \\
\hline Tarragona & 3 & \multicolumn{2}{|c|}{$-4.006 * * *$} & 0.097 & 0 & $-4.002 * * *$ & 0.096 & 0.645 & 3.100 \\
\hline Teruel & 1 & \multicolumn{2}{|c|}{$-3.876^{* * * *}$} & 0.199 & 1 & $-4.062 * * *$ & $0.147 * *$ & 0.778 & 2.225 \\
\hline Toledo & 4 & -3.4 & $3 * * *$ & $0.704 * * *$ & 4 & $-3.980 * * *$ & 0.062 & 0.816 & 1.779 \\
\hline Valencia & 0 & -5.6 & $2 * * *$ & 0.096 & 0 & $-5.747 * * *$ & 0.049 & 0.687 & 1.853 \\
\hline Valladolid & 0 & -3.1 & $9 * * *$ & 0.107 & 0 & $-3.241 * * *$ & 0.081 & 0.744 & 1.807 \\
\hline Zamora & 0 & -2.0 & $1 * *$ & 0.139 & 0 & $-2.738 * *$ & $0.129 * *$ & 0.751 & 1.290 \\
\hline Zaragoza & 1 & -5.9 & $6 * * *$ & 0.036 & 1 & $-6.000 * * *$ & 0.035 & 0.581 & 3.021 \\
\hline $\begin{array}{l}\text { Critical } \\
\text { values }\end{array}$ & & & & & & & & & \\
\hline & $1 \%$ & -2.5 & & 0.536 & & -3.167 & 0.185 & & \\
\hline & $5 \%$ & -1.9 & & 0.324 & & -2.577 & 0.122 & & \\
\hline & $10 \%$ & -1.6 & & 0.235 & & -2.314 & 0.098 & & \\
\hline Bai and $\mathrm{Ng}$ & (2004a) po & oled stati & stics & & & & & & \\
\hline & $P_{\hat{e}}^{c}$ & 809.4 & $7 * * *$ & N.A. & $P_{\hat{e}}^{\tau}$ & $810.675 * * *$ & N.A. & & \\
\hline & $Z_{\hat{e}}^{c}$ & 50.1 & $6 * * *$ & N.A. & $Z_{\hat{e}}^{\tau}$ & $50.252 * * *$ & N.A. & & \\
\hline Bai and $\mathrm{Ng}$ & (2010) poo & led statis & ics & & & & & & \\
\hline & $P_{a}^{c}$ & -70.3 & $2 * * *$ & & $P_{a}^{\tau}$ & $-51.347 * * *$ & & & \\
\hline & $P_{b}^{c}$ & -17.3 & $10 * * *$ & & $P_{b}^{\tau}$ & $-18.592 * * *$ & & & \\
\hline & $\mathrm{PMSB}^{c}$ & -4.9 & $2 * * *$ & & $\mathrm{PMSB}^{\tau}$ & $-6.358 * * *$ & & & \\
\hline Common & Statistic & Critical & alues & & & Statistic & Critical va & alues & \\
\hline analysis & & $1 \%$ & $5 \%$ & $10 \%$ & & & $1 \%$ & $5 \%$ & $10 \%$ \\
\hline $\mathrm{ADF}_{\hat{F}}^{c}$ & $-2.783^{*}$ & -3.430 & -2.860 & -2.570 & $\mathrm{ADF}_{\hat{F}}^{\tau}$ & $-3.427 * *$ & -3.960 & -3.410 & -3.120 \\
\hline$S_{\hat{F}}^{c}$ & $1.185^{* * *}$ & 0.743 & 0.463 & 0.343 & $S_{\hat{F}}^{\tau}$ & $0.371 * * *$ & 0.215 & 0.149 & 0.120 \\
\hline
\end{tabular}

The augmented autoregressions employed in the ADF analysis select the optimal lag-order with the $t$-sig criterion of $\mathrm{Ng}$ and Perron (1995), setting a maximum lag-order equal to $p=4(T / 100)^{1 / 4}$. The stationarity tests are based on 12 lags of the Quadratic spectral kernel. The information criterion $B I C_{3}$ has chosen an optimal rank equal to $1 . P_{\hat{e}}$ is distributed as $\chi_{100}^{2}$, with 1,5 and $10 \%$ critical values of 135.807 , 124.342 and 118.498 , respectively. $Z_{\hat{e}}$ is distributed as $N(0,1)$ with 1,5 and $10 \%$ critical values equal to 2.326, 1.645 and 1.282, respectively. $P_{a}, P_{b}$ and PMSB are distributed as $N(0,1)$ with 1,5 and $10 \%$ critical values of $-2.326,-1.645$ and -1.282 , respectively. $* * *, * *$ and $*$ imply rejection of the null hypothesis at 1,5 and $10 \%$, respectively 
maximum number of factors to five). These criteria clearly point to the existence of only one common stochastic factor. ${ }^{30}$ Thus, if the common factor is found to be nonstationary, and the idiosyncratic components are $I(0)$ stationary, there would be evidence of pair-wise cointegration among the inflation rate series pertaining to the panel.

We next turn to testing for a unit root in the idiosyncratic series. The evidence seems to mostly favor stationarity of the idiosyncratic series even at the univariate level since the unit root null is rejected with the ADF statistic for all the provincial series at the $1 \%$ level, except for three provinces (Córdoba, Las Palmas and Zamora) for which the null is rejected at the $5 \%$. The application of the Shin statistic (as the presence of one nonstationary common factor kept us from using the KPSS test) renders confirmatory evidence of stationarity for 37 provinces. For the rest (13 provinces), the evidence appears inconclusive as the stationarity null is also rejected in this case (for 3 provinces at the $1 \%$ level of significance, 5 at the $5 \%$ and 5 at the $10 \%$ ), as occurred with the unit root null with the ADF statistic. ${ }^{31}$ To supply evidence of the stochastic properties of the idiosyncratic component for the panel as a whole, we apply the pooled Fisher-type inverse Chi square tests of Maddala and Wu (1999) and Choi (2001) along with the PANIC pooled Moon-Perron and Sargan-Bhargava statistics. It is worth highlighting that we are able to reject the joint non-stationarity null hypothesis with the five pooled statistics at the $1 \%$ level of significance, regardless of the inclusion of deterministic trends in the idiosyncratic series specifications. Hence, there is overwhelming evidence of the joint stationarity of the idiosyncratic component of the panel under study.

Columns 8 and 9 of Table 3 show the ratio of the standard deviation of the idiosyncratic component to the standard deviation of the observed data (both expressed in first-differences), and the ratio of the standard deviation of the common component to the standard deviation of the idiosyncratic component respectively, to get a sense of the relative importance of the common and idiosyncratic components. The average values of those ratios are 0.69 and 2.32 , respectively. ${ }^{32}$

Overall, the finding that the source of non-stationarity in the panel is a common stochastic trend driving the non-stationarity in the observed series has become apparent. Both this fact and the presence of a jointly stationary idiosyncratic component combine to render evidence of pairwise cointegration among the Spanish provincial inflation rate series.

\subsubsection{Second period results}

Table 4 presents the results of the univariate ADF and KPSS tests applied to the idiosyncratic series, the respective univariate tests for the common factor as well as

\footnotetext{
${ }^{30}$ Unlike the information criteria to determine the optimal number of common factors (stationary and non-stationary) in Bai and $\mathrm{Ng}(2004 \mathrm{a}, \mathrm{b})$ that are applied to data in first-differences, the IPC $_{\mathrm{p}}$ panel information criteria to determine the number of non-stationary common factors proposed by Bai (2004) are applied to level data. In addition, the consistency of Bai (2004)'s information criteria requires the idiosyncratic component to be $I(0)$, which we will find below to be the case.

31 These results are very similar for the trend specification.

32 As laid out by Bai and $\mathrm{Ng}$ (2004b), if all variations are idiosyncratic, the first ratio should take a value close to one, while the second should be small.
} 


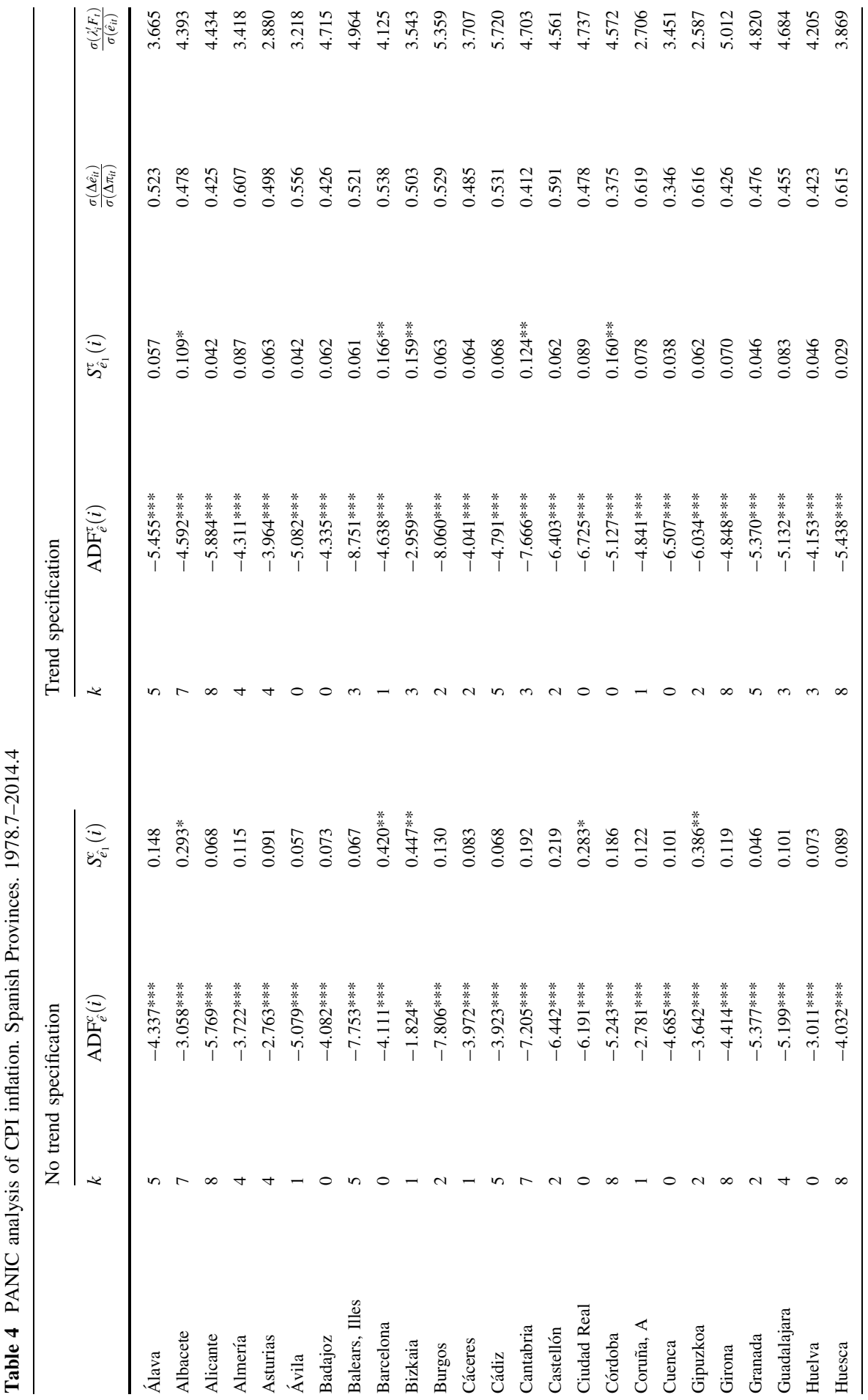




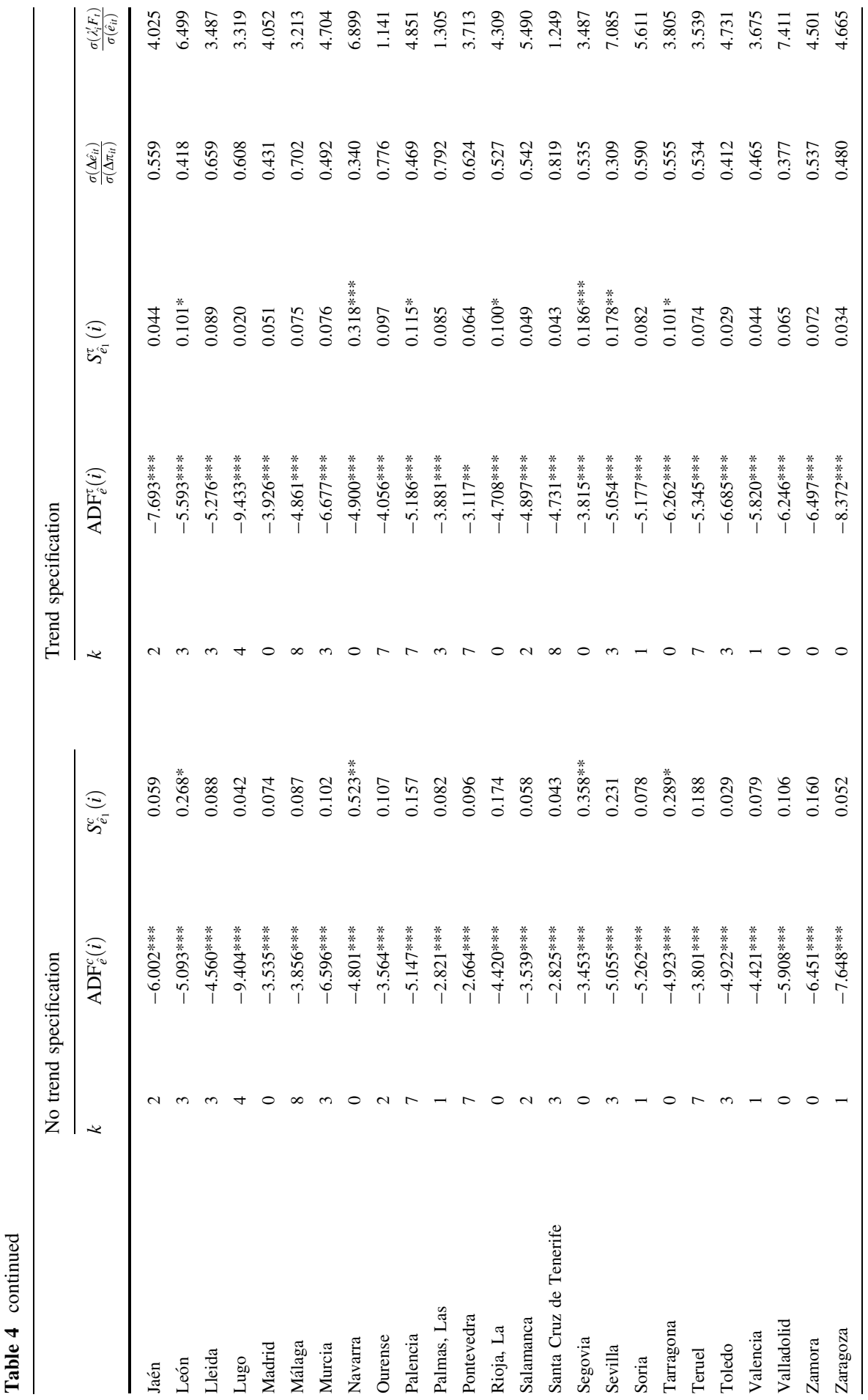




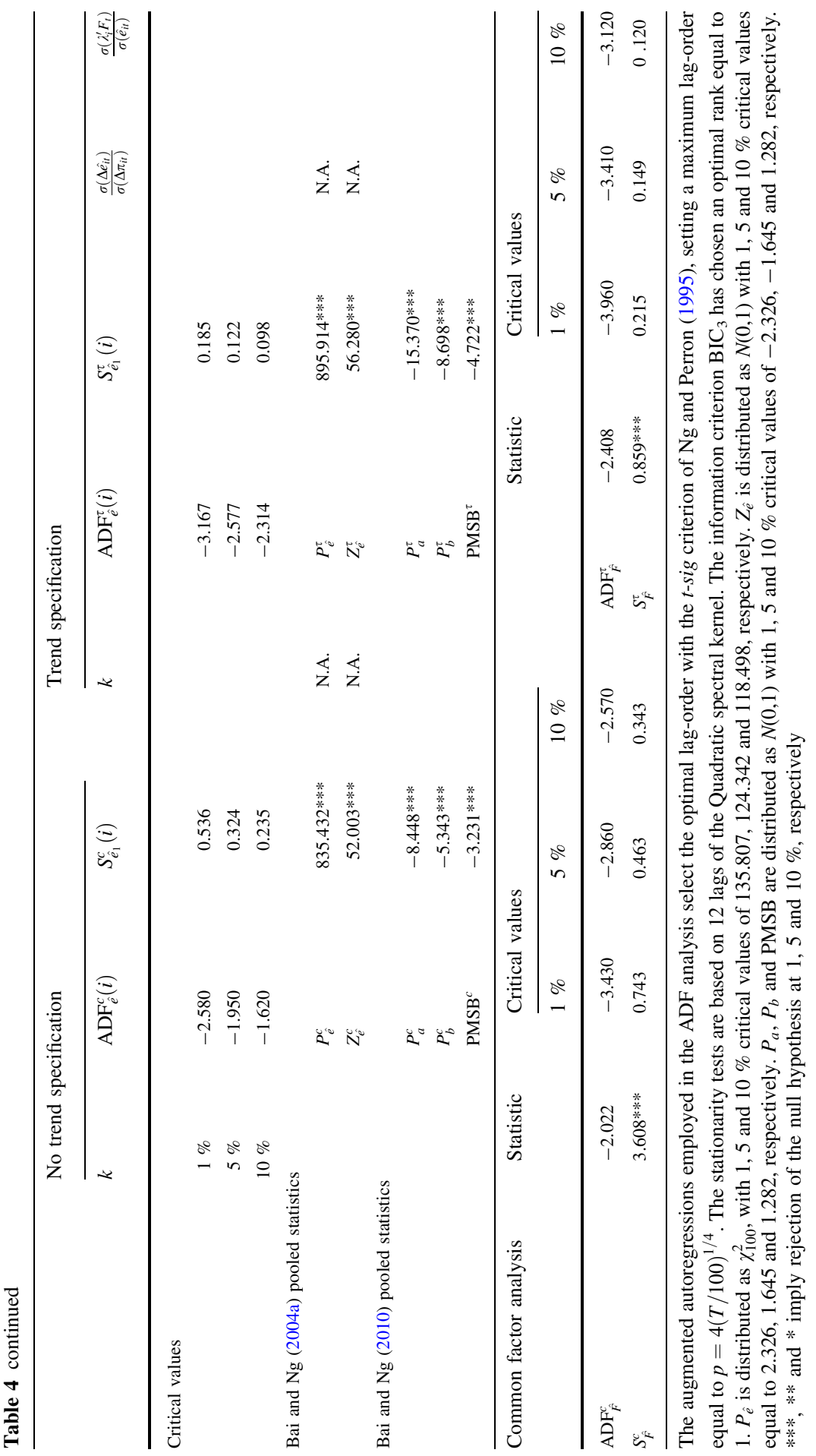


the pooled statistics of Bai and $\mathrm{Ng}(2004 \mathrm{a}, 2010)$ for the second panel covering the period 1978.7-2014.4.

Again our aim is to discover the source of non-stationarity in Spanish provincial inflation. In this case, the $\mathrm{BIC}_{3}$ procedure again selected only one common factor and there is clear evidence of a unit root in the common factor, since the unit root null is not rejected with the $\mathrm{ADF}_{\hat{F}}^{c}$ test and the stationarity null is strongly rejected with the $\operatorname{KPSS}_{\hat{F}}^{c}$ statistic. This result carries over to the trend specification.

We now proceed to test for a unit root in the idiosyncratic series. The evidence appears to lend support to the stationarity of the idiosyncratic series even at the univariate level since the unit root null is rejected with the ADF statistic for 49 provinces at the $1 \%$ significance level and for one province at the $10 \%$ level (Bizkaia). The application of the Shin statistic yields confirmatory evidence of stationarity for 41 provinces. For the rest (nine provinces), the evidence appears inconclusive as the stationarity null is also rejected in this case (for 5 at the $5 \%$ significance level and for 4 at the $10 \%$ ), as happened to the unit root null with the ADF statistic. ${ }^{33}$ Regarding the stochastic properties of the idiosyncratic component for the panel as a whole, it should be stressed that, as in the previous case, we are able to reject the joint non-stationarity null hypothesis with the five pooled statistics at the $1 \%$ level of significance, irrespective of the inclusion of deterministic trends in the specifications. Therefore, also for this period overwhelming evidence of the joint stationarity of the idiosyncratic component of the panel exists.

Columns 8 and 9 of Table 4 supply the aforementioned ratios of standard deviations. The average values are now 0.52 and 4.22, respectively (they were 0.69 and 2.32 in the previous case). This change in those values points towards a higher importance of the common component in this second period of our analysis, which implies a stronger link among the provincial inflation rate series. This in turn indicates that convergence among provincial inflation rate series has occurred to a larger extent over the second period under study.

In sum, the panel tests applied to the idiosyncratic component support the joint stationarity of the idiosyncratic series. This, combined with the presence of a nonstationary common factor, provides evidence of pairwise cointegration among the provincial inflation rate series in both periods under scrutiny, and especially in the second one. These results fit in with prior studies about Spanish inflation persistence and the hypothesis we aim to validate in this work regarding the inflation convergence across Spanish provinces, particularly after the late 70 s. $^{34}$

\footnotetext{
33 The results are very similar for the trend specification.

34 For robustness purposes, we explicitly incorporated the possibility of structural breaks into the statistical analysis using the PANIC methodology by computing the three PANIC panel unit root tests proposed by Bai and Carrión-i-Silvestre (2009), which allow for multiple structural breaks and common factors. These tests include the $Z$ test distributed as a lower-tailed standard normal distribution, the Fishertype $P_{m}$ statistic distributed as an upper-tailed standard normal distribution and the Fisher-type $P$ statistic distributed as a $\chi_{2 N}^{2}$. In computing the three panel unit root tests, we allow for five common factors as well as for up to five mean shifts in the no-trend specification and five mean and slope shifts in the trend specification. Irrespective of the inclusion of a trend in the specification, the three panel unit root tests (which take on a value of $-5.963,101.026$ and 1528.72 for the no-trend specification and -7.478 , 114.825 and 1723.867 for the trend specification, respectively) reject the joint unit root null hypothesis, in favor of the stationarity of the idiosyncratic component. This is the same result we found when applying the standard PANIC approach to the two sub-periods separately.
} 


\subsection{Pairwise test of Pesaran}

As an alternative test of pairwise convergence to PANIC, we employ the pairwise test developed by Pesaran (2007a). Pairwise convergence among the $N(N-1) / 2$ pairs (1225) of provincial inflation rates requires the existence of cointegrating relations of the series involved of the form $(1,-1)$. This corresponds to the presence of stationarity for all possible pairs of inflation rates: $d_{t}^{i, j}=\pi_{t}^{i}-\pi_{t}^{j}, i=1 \ldots N-1$ and $j=i+1 \ldots N$. Following Pesaran (2007a), we test whether all crossprovincial inflation differentials (pairs) are stationary with the ADF test and a more powerful variant of the ADF statistic given by the weighted-symmetric (WS) test proposed by Park and Fuller (1995) as well as the KPSS statistic. For the former two tests, under the null of a unit root (i.e., non-convergence), the fraction of inflation rate gap pairs for which the null hypothesis is rejected should converge to the size of the unit root tests applied to individual inflation gap pairs, for $N$ and $T \rightarrow \infty$. Hence, if there is rejection of the non-convergence null for a proportion of the inflation gap pairs higher than any reasonable test size (e.g. 10 or $5 \%$ ), the evidence would be favorable to convergence. Table 5 presents the results of the fraction of rejections based on the 5 and $10 \%$ nominal level tests for both periods for the case of an intercept only and for a specification with an intercept and a linear trend. The results for the ADF and WS tests are calculated setting a maximum lag order of eight, thereby choosing the optimal lag order with either the Akaike information criterion (AIC) or the Schwarz Bayesian criterion (SBC). The results for the KPSS statistic are calculated using a bandwidth that rounds $0.75 \times T^{1 / 3} .35$

As can be observed in Table 5, we find evidence of a fraction of rejections close to 1 for both periods with the ADF and WS unit root tests, irrespective of the inclusion of a linear trend in the specification. This indicates that all provincial inflation rate pairs have converged to each other, thus confirming the pairwise convergence finding obtained with PANIC. However, according to the KPSS stationarity test, the null of convergence is rejected for a fraction higher than the nominal size, ranging from about 0.20 and 0.40 . This would indicate the existence of a lower proportion (than 1) of inflation rate pairs converging to each other. Given the size distortions that the univariate KPSS test tends to exhibit, we base our conclusions on the basis of the ADF and WS unit root tests, which point to the existence of pairwise convergence in both periods.

\section{Convergence analysis}

\subsection{Multivariate regression analysis}

The PANIC analysis we have performed shows that, mainly in the second period, there is convergence in the provincial inflation rates. Accordingly, digging deeper into the information about convergence, in the supplementary appendix we provide

\footnotetext{
35 This analysis is conducted with GAUSS routines kindly provided by Hashem Pesaran at http://pesaran. $\mathrm{com} /$.
} 
Table 5 Pairwise test of Pesaran (2007a)

\begin{tabular}{|c|c|c|c|c|}
\hline & \multicolumn{2}{|c|}{ No trend specification } & \multicolumn{2}{|l|}{ Trend specification } \\
\hline & $\begin{array}{l}\text { CPI. } 50 \text { provinces. } \\
1955.1-1978.6\end{array}$ & $\begin{array}{l}\text { CPI. } 50 \text { provinces. } \\
1978.7-2014.4\end{array}$ & $\begin{array}{l}\text { CPI. } 50 \text { provinces. } \\
1955.1-1978.6\end{array}$ & $\begin{array}{l}\text { CPI. } 50 \text { provinces. } \\
1978.7-2014.4\end{array}$ \\
\hline \multicolumn{5}{|c|}{ Fraction of rejections, based on $5 \%$ nominal level tests } \\
\hline \multicolumn{5}{|c|}{ Lag order chosen with AIC } \\
\hline $\begin{array}{l}\text { Average } \\
\text { lag-order }\end{array}$ & 4.256 & 6.896 & 4.317 & 6.977 \\
\hline ADF test & 0.985 & 0.999 & 0.952 & 0.995 \\
\hline WS test & 0.999 & 0.993 & 0.985 & 0.974 \\
\hline \multicolumn{5}{|c|}{ Lag order chosen with SBC } \\
\hline $\begin{array}{l}\text { Average } \\
\text { lag-order }\end{array}$ & 1.345 & 2.508 & 1.324 & 2.536 \\
\hline ADF test & 0.998 & 0.999 & 0.984 & 0.994 \\
\hline WS test & 0.999 & 0.994 & 0.997 & 0.979 \\
\hline KPSS test & 0.228 & 0.202 & 0.299 & 0.303 \\
\hline \multicolumn{5}{|c|}{ Fraction of rejections, based on $10 \%$ nominal level tests } \\
\hline \multicolumn{5}{|c|}{ Lag order chosen with AIC } \\
\hline $\begin{array}{l}\text { Average } \\
\text { lag-order }\end{array}$ & 4.256 & 6.896 & 4.317 & 6.977 \\
\hline ADF test & 0.997 & 1.000 & 0.979 & 0.998 \\
\hline WS test & 1.000 & 0.994 & 0.995 & 0.984 \\
\hline \multicolumn{5}{|c|}{ Lag order chosen with SBC } \\
\hline $\begin{array}{l}\text { Average } \\
\text { lag-order }\end{array}$ & 1.345 & 2.508 & 1.324 & 2.536 \\
\hline ADF test & 0.999 & 1.000 & 0.997 & 0.999 \\
\hline WS test & 1.000 & 0.997 & 0.999 & 0.989 \\
\hline KPSS test & 0.352 & 0.305 & 0.444 & 0.409 \\
\hline
\end{tabular}

WS denotes the weighted-symmetric statistic of Park and Fuller (1995). AIC and SBC denote Akaike information criterion and Schwarz Bayesian criterion, respectively. A maximum lag order of 8 is allowed in the computation of the ADF and WS statistics. The bandwidth for the KPSS test is int $\left(0.75 \times T^{1 / 3}\right)$

results on how much the coefficient of variation ${ }^{36}$ changes (in terms of percentage of variation) from the start of each period up to its midpoint and from the beginning of each period up to its end, for an ample group of relevant variables that include the inflation rate and some of its potential determinants (the unemployment rate, two proxies for the real average wage, two proxies for the labor share in the GVA, nominal and real unit labor cost (ULC), real GVA per capita and real labor productivity). ${ }^{37} \mathrm{~A}$ negative sign in the table means (sigma) convergence in the

\footnotetext{
36 In the case of the inflation rate, the information refers to the standard deviation.

37 The data are mainly based on De la Fuente (2010), Encuesta de Población Activa (EPA)— unemployment - and CPI (inflation). Globalization and some other institutional features like central bank independence and sound fiscal policies are likely contributors to inflation convergence, but such hypotheses are not examined explicitly in the paper.
} 


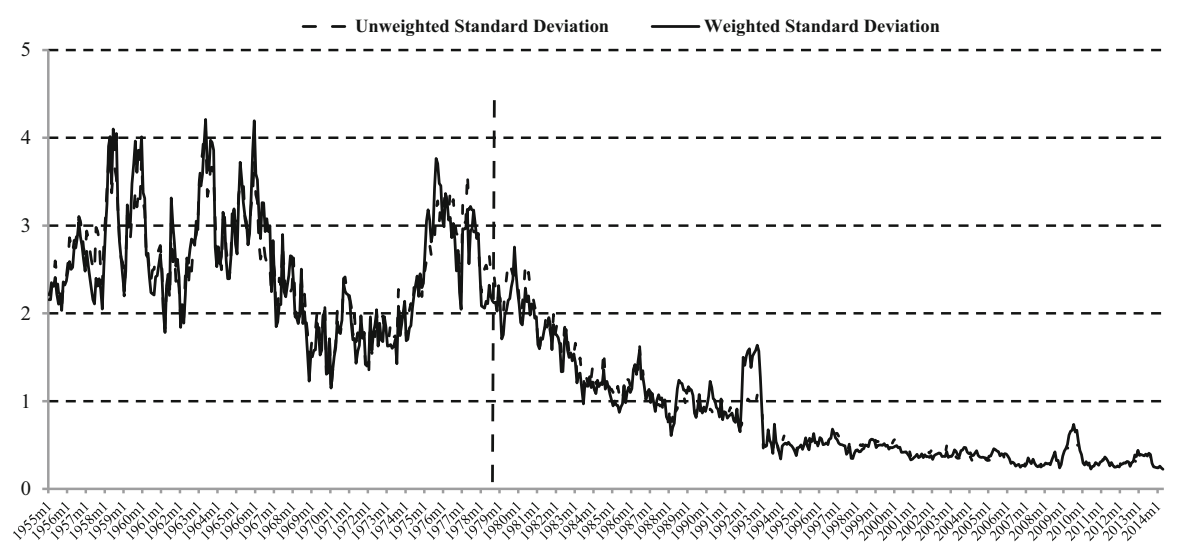

Fig. 2 Evolution of the standard deviation. Spanish provincial inflation rates. 1955.1-2014.4

variable involved, and a positive one just the opposite. It is quite visible that widespread convergence in the variables occurs over time. It is also remarkable that this convergence process is stronger throughout the second period (the real GVA per capita being the only exception). ${ }^{38}$ Overall, the broad pattern of convergence is illustrated in Fig. 2, particularly over the second period under scrutiny, thus confirming the results derived via PANIC analysis.

We next try to compare our study with that of Beck et al. (2009), an important reference in this field, which included the Spanish regions. However, the comparison can be only partial, due to some differences in the characteristics of our respective analyses. In our analysis, the dependent variable is the common factor obtained from the PANIC analysis of Spanish provincial inflation and we will use average national data as explanatory variables. Our series are expressed in time series form and they are generally long. In Beck et al. (2009) the dependent variable is regional inflation and they use the respective regional data as explanatory variables. Their analysis is in cross-section form and they only study a short period of time (1995-2004) for six European countries. They obtain their main conclusions from mean regional relations.

For this comparison, we have compiled several proxies trying to follow Beck et al. (2009)'s approach: (1) real ULC, as a way to capture the fact that different regional developments in the price of labor (i.e., wages), potentially caused by geographic labor market fragmentation, may lead to persistent inflation differentials. (2) Inter-annual growth in the COICOP index "Housing, water, electricity, gas and other fuels" (data source: Eurostat). It is a measure of costs of non-wage input factors, whose geographic differences may stem from supply and demand changes in segmented markets or structural inefficiencies in regulated markets (Beck et al. 2009). (3) Oil price inflation (dollars per barrel, data source: Reuters). It is also a

\footnotetext{
38 A widely known outcome for the Spanish economy: after some decades of convergence of this variable, many years of unclear evolution followed. On the regional convergence of the Spanish economy and related factors, see Cuadrado-Roura (2010).
} 
measure of costs of non-wage input factors - this variable is not analyzed by Beck et al. (2009) but we consider its inclusion to be relevant for the Spanish case. (4) The unemployment rate that accounts for a region's position in the business cycle and for the potential effect of labor market heterogeneity - caused by the geographic segmentation of labor markets - on inflation differentials. (5) Ratio: number of local units with three or more employees/population (in thousands). Data source: Directorio Central de Empresas (DIRCE) and population figures, both from INE. It is a measure of the market density in the manufacturing and wholesale sector (i.e., the number of suppliers), proxying for the competitive structure of a region, with a higher value implying a greater degree of competition. As pointed out by Beck et al. (2009), nominal rigidities are generally associated with imperfect competition in the goods and labor markets leading to a high degree of inflation persistence, which can be responsible for permanent inflation differentials. (6) Share of services in GVA at basic prices (data source: Contabilidad Nacional Trimestral de España, INE). It is one of the proxies used by Beck et al. (2009) to capture the economic structure, which can be the origin of asymmetric shocks and differences in the transmission of such shocks. Cross-regional differences in economic structure are conducive to asynchronous business cycle developments, which can at least have a transitory effect on inflation differentials. (7) The growth rate of real GVA per capita, as a way to capture the Balassa-Samuelson effect. Higher economic growth rates are generally associated with a higher price level for non-tradable goods, and in turn a higher overall price level. Hence, the price level will rise by a greater amount in fast-growing provinces relative to slow-growing ones, thus causing inflation differentials. In all, we have tried to follow as much as possible the spirit (and the specifications) of their exercise-see mainly Beck et al. (2009, pp. 161, 162).

It is worth noting that, in comparison with bivariate analyses (common factor vs. each one of the aforementioned variables), the multivariate regression presents two main problems: (1) once you combine the different samples corresponding to the different variables involved, the joint time period of analysis is shortened-mainly due to the shorter samples of the additional variables following Beck et al. (2009)—, with the results corresponding only to a part of our second period of analysis. (2) The analysis faces severe potential multicollinearity problems-remember that in some cases we work with different proxies for the same type of variable and in other cases some of our variables embed or include other variables. Due to some problems with the data and the econometric methods already pointed out, Beck et al. (2009) only introduced a reduced group of variables in their multivariate analysis to explain inflation (for all the countries of their study): unemployment rate, real ULC, COICOP group index growth, competition proxy, percentage of services and real GVA per capita growth. Of those variables, only three resulted significant: COICOP group index growth $(+)$, competition proxy $(-)$, and percentage of services $(-)$.

In our case, for the Spanish economy, we have tried to replicate the structure of that multivariate exercise, even playing in some cases with different proxies for the same type of variable. In this sense, Table 6 provides robust significant coefficients for the following variables: unemployment rate $(-)$, real ULC $(+)$, COICOP group 
Table 6 Determinants of the common component of province-level inflation

(1)

$$
\begin{aligned}
& -0.138 * * *(-4.87) \\
& 6.868 * * *(8.23) \\
& 0.141 *(1.80)
\end{aligned}
$$

COICOP group inflation rate

Oil inflation rate

Services share

Market density

Real GVA per capita growth

Constant

F-statistic

$R^{2}$
(2)

$$
\begin{aligned}
& -0.138 * * *(-4.85) \\
& 6.879 * * *(8.33) \\
& 0.0078 * *(2.03) \\
& -0.063 * * *(-5.46) \\
& -0.341 * * *(-16.40) \\
& -5.231 * * *(-7.50) \\
& 7.456 * * *(9.09) \\
& 177.30 * * * \\
& 0.706
\end{aligned}
$$

$t$-statistics are presented in parenthesis

$* * *, * *$ and $*$ imply statistically significant coefficients at the 1,5 and $10 \%$ level, respectively

index growth $(+)$, oil price inflation $(+)$, competition proxy $(-)$, services share in GVA (-), and real GVA per capita growth (-).

Concerning labor market variables, both the unemployment rate and the real ULC appear to explain the inflation rate. In the case of the unemployment rate, the negative sign of its coefficient appears to be consistent with the Phillips curve, which accounts for the negative relation between the inflation and unemployment rates. ${ }^{39}$ The significantly positive coefficient on the real ULC indicates the existence of a positive relation between developments in the price of labor and persistent developments in inflation. All this suggests that labor market institutions can affect costs of production and in turn the inflation rate. The multivariate specification also offers consistent evidence of the positive impact that increases in non-wage input factor prices (measured either through the growth in the COICOP index "Housing, water, electricity, gas and other fuels" or the oil inflation rate) exert on the inflation rate, thus reducing the degree of competitiveness of the Spanish economy. In addition, market density, which proxies for the competitive structure of the Spanish economy, appears to be inversely related to the inflation rate. This indicates that the larger the number of suppliers and the higher the degree of competition, the lower the inflation rate. In line with Beck et al. (2009) findings, the services share in GVA is negatively associated with the inflation rate. This supports the fact that asymmetric shocks caused by sectoral specialization can exert a temporary effect on the inflation rate. Finally, the significant negative coefficient on the growth rate of real GVA per capita runs counter to the positive sign predicted by the BalassaSamuelson hypothesis. This appears in line with other studies for European cities or regions like Rogers (2007) and Beck et al. (2009), and with previous evidence for Spain.

\footnotetext{
39 Although it should be pointed out that the evidence about the Spanish Phillips curve mainly indicates a weak relation between inflation and unemployment - see for example the survey by Gómez and Usabiaga (2001) and Caraballo and Usabiaga (2009b).
} 


\subsection{Analysis of weightings in the shopping basket}

An alternative explanation of the acute convergence path found in the provincial inflation rates in the second time period could be ascribed to the fact that the composition of the shopping basket in the Spanish provinces has tended to become more homogeneous over time. This phenomenon can be approached by paying close attention to the provincial weightings attached to the different groups of goods and services the CPI comprises. In this particular analysis, we will thus heed the CPI breaking down into twelve groups of goods and services-the so-called COICOP-, although it could also be accomplished with a greater disaggregation-for the subgroups, which are in effect more than thirty. ${ }^{40}$

Unfortunately, lack of data availability prevents us from carrying out this examination for the first period. However, we can state something on that matter regarding the second period, as we are able to compare the figures of the years 1992 and 2014 — chronologically speaking, they are the first year and the most recent one, respectively, for which there are CPI weightings data available. ${ }^{41}$

For each COICOP group of goods and services (12) we will look into the coefficient of variation of its weightings across provinces (50). Thus, if this statistic decreases over time (sigma convergence), it means that the different provinces are allocating a more similar weighting to each specific group, which constitutes a neat convergence process in the different provinces' shopping basket. Given that this is a relevant complementary exploration aimed at deriving robust outcomes from our investigation, we deal with four kinds of standard deviation (unweighted, weighted by provincial GDP, weighted by provincial employment and weighted by provincial population). Table 7 provides the percentage change of each coefficient of variation between 1992 and the last year for which the calculation can be done. For this reason, each negative sign in the table - reduction of the coefficient of variationindicates (sigma) convergence. As can be easily seen, for all groups there is overall evidence of convergence in the weightings assigned by the various provinces. Only in the particular case of group 4 (Housing), for the coefficient of variation obtained through the GDP-weighted standard deviation, is convergence not observed. This is not surprising since Housing constitutes a clear example of a non-tradable good, for which convergence across provinces is more difficult to realize relative to tradable goods.

In short, during our second time period examined, it is shown that the Spanish provinces' shopping basket tends to converge in a clear way, which could help to further account for the strong perceived convergence among the Spanish provincial inflation rates.

\footnotetext{
${ }^{40}$ Given the robustness of our results as regards COICOP groups, we have not deemed it necessary to break down the data further into sub-groups.

${ }^{41}$ Given that, in order to weight the standard deviation, we cross-check those CPI weightings with some other variables' data, all at a provincial level, the reference period will finally be 1992 vs. 2013 (and 2011 when appropriate).
} 
Table 7 Coefficient of variation of the weightings of the CPI-based groups of goods and services in the different Spanish provinces. Difference from 1992 (\%)

\begin{tabular}{|c|c|c|c|c|}
\hline Group & $\begin{array}{l}\text { With } \\
\text { unweighted } \\
\text { standard } \\
\text { deviation. } \\
2013\end{array}$ & $\begin{array}{l}\text { With standard } \\
\text { deviation } \\
\text { weighted by } \\
\text { provincial GDP. } \\
2011\end{array}$ & $\begin{array}{l}\text { With standard } \\
\text { deviation weighted } \\
\text { by provincial } \\
\text { employment. } 2013\end{array}$ & $\begin{array}{l}\text { With standard } \\
\text { deviation weighted } \\
\text { by provincial } \\
\text { population. } 2013\end{array}$ \\
\hline $\begin{array}{l}\text { G1. Food and non- } \\
\text { alcoholic beverages }\end{array}$ & -23.50 & -4.76 & -14.51 & -15.12 \\
\hline $\begin{array}{l}\text { G2. Alcoholic } \\
\text { beverages and } \\
\text { tobacco }\end{array}$ & -17.44 & -11.74 & -21.27 & -22.67 \\
\hline $\begin{array}{l}\text { G3. Clothing and } \\
\text { footwear }\end{array}$ & -9.87 & -6.00 & -13.87 & -15.62 \\
\hline G4. Housing & -28.74 & +6.90 & -10.11 & -11.66 \\
\hline $\begin{array}{l}\text { G5. Furnishings, } \\
\text { household equipment } \\
\text { and routine } \\
\text { maintenance of the } \\
\text { house }\end{array}$ & -29.82 & -3.83 & -19.41 & -18.06 \\
\hline G6. Health & -33.32 & -39.99 & -47.13 & -46.71 \\
\hline G7. Transport & -25.42 & -9.25 & -22.63 & -22.89 \\
\hline G8. Communications & -55.44 & -42.53 & -53.49 & -52.87 \\
\hline $\begin{array}{l}\text { G9. Recreation and } \\
\text { culture }\end{array}$ & -22.91 & -3.26 & -13.87 & -14.75 \\
\hline G10. Education & -28.03 & -25.92 & -28.81 & -30.31 \\
\hline $\begin{array}{l}\text { G11. Restaurants, cafés } \\
\text { and hotels }\end{array}$ & -23.65 & -23.55 & -35.27 & -34.08 \\
\hline $\begin{array}{l}\text { G12. Miscellaneous } \\
\text { goods and services }\end{array}$ & -50.10 & -51.31 & -54.45 & -54.66 \\
\hline
\end{tabular}

\subsection{Testing the Balassa-Samuelson hypothesis using Pesaran's (2007a) approach}

As a final exercise aimed at more formally determining the extent of convergence in each of the 12 COICOP groups of goods and services across the 50 provinces forming Spain, we apply the pairwise convergence approach of Pesaran (2007a) to each of these groups of goods and services over the 1994.1-2015.11 period. This exercise, in line with that conducted by Yilmazkuday (2013), constitutes an indirect way to assess whether the Balassa-Samuelson hypothesis holds across the Spanish provinces over the period under scrutiny. If this hypothesis is to hold, convergence among pairs of provincial inflation rates should be more prevalent in those groups involving tradable goods, since cross-province trade would help eliminate inflation differentials. In contrast, for those groups mainly composed of non-tradable goods and services, a lower extent of convergence among provincial inflation pairs is 
Table 8 Pairwise test of Pesaran (2007a) applied to COICOP groups. 1994.1-2015.11

\begin{tabular}{|c|c|c|c|c|}
\hline & \multicolumn{2}{|c|}{ No trend specification } & \multicolumn{2}{|l|}{ Trend specification } \\
\hline & $\begin{array}{l}\text { Lag order chosen } \\
\text { with AIC }\end{array}$ & $\begin{array}{l}\text { Lag order chosen } \\
\text { with SBC }\end{array}$ & $\begin{array}{l}\text { Lag order chosen } \\
\text { with AIC }\end{array}$ & $\begin{array}{l}\text { Lag order chosen } \\
\text { with SBC }\end{array}$ \\
\hline \multicolumn{5}{|c|}{ G1. Food and non-alcoholic beverages } \\
\hline $\begin{array}{l}\text { Average lag- } \\
\text { order }\end{array}$ & 5.882 & 1.818 & 6.064 & 1.884 \\
\hline ADF test & 0.980 & 0.968 & 0.912 & 0.843 \\
\hline WS test & 0.990 & 0.996 & 0.951 & 0.921 \\
\hline \multicolumn{5}{|c|}{ G2. Alcoholic beverages and tobacco } \\
\hline $\begin{array}{l}\text { Average lag- } \\
\text { order }\end{array}$ & 6.277 & 2.228 & 6.395 & 2.305 \\
\hline ADF test & 0.992 & 0.976 & 0.961 & 0.897 \\
\hline WS test & 0.987 & 0.989 & 0.966 & 0.934 \\
\hline \multicolumn{5}{|c|}{ G3. Clothing and footwear } \\
\hline $\begin{array}{l}\text { Average lag- } \\
\text { order }\end{array}$ & 6.856 & 3.320 & 6.979 & 3.251 \\
\hline $\mathrm{ADF}$ test & 0.873 & 0.923 & 0.845 & 0.885 \\
\hline WS test & 0.878 & 0.918 & 0.838 & 0.889 \\
\hline \multicolumn{5}{|l|}{ G4. Housing } \\
\hline $\begin{array}{l}\text { Average lag- } \\
\text { order }\end{array}$ & 4.929 & 1.608 & 5.219 & 1.624 \\
\hline $\mathrm{ADF}$ test & 0.990 & 0.970 & 0.941 & 0.792 \\
\hline WS test & 0.996 & 0.992 & 0.981 & 0.934 \\
\hline \multicolumn{5}{|c|}{ G5. Furnishings, household equipment and routine housing maintenance } \\
\hline $\begin{array}{l}\text { Average lag- } \\
\text { order }\end{array}$ & 3.760 & 1.080 & 3.986 & 1.090 \\
\hline ADF test & 0.994 & 0.999 & 0.967 & 0.985 \\
\hline WS test & 0.999 & 1.000 & 0.989 & 0.998 \\
\hline \multicolumn{5}{|l|}{ G6. Health } \\
\hline $\begin{array}{l}\text { Average lag- } \\
\text { order }\end{array}$ & 5.050 & 1.456 & 5.526 & 1.487 \\
\hline $\mathrm{ADF}$ test & 0.996 & 0.983 & 0.968 & 0.889 \\
\hline WS test & 0.998 & 0.996 & 0.993 & 0.948 \\
\hline \multicolumn{5}{|l|}{ G7. Transport } \\
\hline $\begin{array}{l}\text { Average lag- } \\
\text { order }\end{array}$ & 3.958 & 1.464 & 4.104 & 1.489 \\
\hline ADF test & 0.953 & 0.931 & 0.860 & 0.739 \\
\hline WS test & 0.961 & 0.957 & 0.942 & 0.865 \\
\hline \multicolumn{5}{|c|}{ G8. Communications } \\
\hline $\begin{array}{l}\text { Average lag- } \\
\text { order }\end{array}$ & 1.987 & 1.258 & 2.037 & 1.259 \\
\hline ADF test & 0.584 & 0.603 & 0.451 & 0.476 \\
\hline WS test & 0.745 & 0.770 & 0.500 & 0.537 \\
\hline
\end{tabular}


Table 8 continued

\begin{tabular}{|c|c|c|c|}
\hline No trend specificat & & Trend specification & \\
\hline $\begin{array}{l}\text { Lag order chosen } \\
\text { with AIC }\end{array}$ & $\begin{array}{l}\text { Lag order chosen } \\
\text { with SBC }\end{array}$ & $\begin{array}{l}\text { Lag order chosen } \\
\text { with AIC }\end{array}$ & $\begin{array}{l}\text { Lag order chosen } \\
\text { with SBC }\end{array}$ \\
\hline
\end{tabular}

G9. Recreation and culture

\begin{tabular}{|c|c|c|c|c|}
\hline $\begin{array}{l}\text { Average lag- } \\
\text { order }\end{array}$ & 3.679 & 1.331 & 3.773 & 1.314 \\
\hline ADF test & 0.992 & 0.998 & 0.954 & 0.978 \\
\hline WS test & 0.977 & 0.981 & 0.954 & 0.971 \\
\hline \multicolumn{5}{|l|}{ G10. Education } \\
\hline $\begin{array}{l}\text { Average lag- } \\
\text { order }\end{array}$ & 3.009 & 1.308 & 3.198 & 1.300 \\
\hline ADF test & 0.976 & 0.980 & 0.935 & 0.936 \\
\hline WS test & 0.995 & 0.994 & 0.940 & 0.949 \\
\hline \multicolumn{5}{|c|}{ G11. Restaurants, cafés and hotels } \\
\hline $\begin{array}{l}\text { Average lag- } \\
\text { order }\end{array}$ & 4.151 & 1.273 & 4.345 & 1.277 \\
\hline ADF test & 0.987 & 0.999 & 0.947 & 0.962 \\
\hline WS test & 0.984 & 0.993 & 0.938 & 0.948 \\
\hline \multicolumn{5}{|c|}{ G12. Miscellaneous goods and services } \\
\hline $\begin{array}{l}\text { Average lag- } \\
\text { order }\end{array}$ & 4.230 & 1.376 & 4.461 & 1.408 \\
\hline ADF test & 0.975 & 0.985 & 0.894 & 0.895 \\
\hline WS test & 0.988 & 0.991 & 0.927 & 0.940 \\
\hline
\end{tabular}

WS denotes the weighted-symmetric statistic of Park and Fuller (1995). AIC and SBC denote Akaike information criterion and Schwarz Bayesian criterion, respectively. A maximum lag order of 8 is allowed in the computation of the ADF and WS statistics. The fraction of rejections is based on $5 \%$ nominal level tests

expected. Hence, one would expect a higher degree of convergence for the following groups involving tradable goods and services: food and non-alcoholic beverages, alcoholic beverages and tobacco, clothing and footwear, and transport. A lower degree of convergence is expected in those groups involving a mix of tradables and non-tradables such as furnishings, household equipment and routine housing maintenance, and recreation and culture; and an even lower degree of convergence for those groups involving mainly non-tradables (in most cases services) such as housing, health, communications, education, restaurants, cafés and hotels, and miscellaneous goods and services.

As can be observed in Table 8, there is evidence of a fraction of rejections close to 1 for all the COICOP groups of goods and services, with the exception of the Communications group involving mainly non-tradables, which exhibits a fraction of rejections of the null hypothesis of no convergence of about 0.60 for the case of the ADF statistic and 0.75 for the case of the WS unit root test. These results are generally robust to the inclusion of a linear trend in the specification. Even though we focus in the text on the results obtained when the fraction of rejections is based on the $5 \%$ nominal level tests, the same results hold when the fraction of rejections 
is based on the $10 \%$ nominal level tests. Overall, this indicates that convergence in provincial inflation rates is widespread across groups of goods and services, since provincial inflation rate pairs have converged to each other for most of the groups, irrespective of the tradables/non-tradables distinction. This confirms the pairwise convergence finding obtained for the aggregate provincial CPI-based inflation rates. Aside from the finding supporting a lower extent of pairwise convergence for the Communications group (involving mainly non-tradables), which would accord with the Balassa-Samuelson hypothesis, the bulk of the evidence does not allow us to support the Balassa-Samuelson effect predicting important inflation differentials in non-tradables (which would then be reflected in a relatively low fraction of rejections for those COICOP groups involving non-tradables).

\section{Conclusions}

Our initial hypothesis has proven to be right. The behavior of the Spanish provincial inflation rates differs between the two well-defined periods of time explored, and mainly a stronger convergence pattern is found over the second period. In this work we list a large number of institutional, political and economic changes, both at national and international levels, which might be behind that pattern change. Among the international factors, we underscore the importance of globalization, intensified through economic integration processes, and a well-managed monetary policy as the most powerful causes prompting inflation convergence within Spain. We also ask ourselves whether these forces have somehow played a role in bringing about the same sort of convergence within Latin American countries. Our analysis leads us to think that those countries that have pursued similar economic policies as the Spanish ones are likely to have experienced sub-central inflation convergence as well. For the sake of availability of data and empirical evidence, we have made some comments on the Mexican and the Peruvian cases.

Overall, the PANIC analysis we develop, in addition to demonstrating the notable persistence of Spanish inflation, fits well with the expected results: higher importance of the common component of the series in the second period analyzed which links provincial inflation rate series together, thereby leading to strong convergence. The evidence from the pairwise test of Pesaran appears to largely back up these findings.

Besides inflation, we focus on a battery of economic and labor variables, mostly by scrutinizing regional data, and conclude that they converge as well, mainly throughout our second period of analysis-with the exception of the real GVA per capita, which converges faster in the first period. These variables' convergence at the geographic level is likely to have contributed to inflation's convergence. Delving deeper into that analysis, our multivariate analysis highlights the role of unemployment, the costs of some non-wage input factors, the degree of competition and the services share in GVA. All the signs found on the coefficients are plausible, in terms of the Phillips curve, the non-wage price pressure, the disinflationary competition and sectoral specialization patterns_-given the problems and rigidities of the goods and labor markets in Spain. However, the negative sign of the 
coefficient on real GVA per capita growth does not support the validity of the Balassa-Samuelson effect. A fundamental additional assessment undertaken, only possible for the second period, as the necessary data start in 1992, centres on the weightings given to the CPI's groups of goods and services across Spanish provinces. We arrive at a very robust outcome: those weightings clearly tend to converge. That is, the shopping basket in the Spanish provinces has become more homogenous over the second period of our analysis. Finally, when we disaggregate provincial CPI-based inflation rates into province-level inflation rates of the 12 COICOP groups of goods and services, we find that, with the exception of the Communications group involving mainly non-tradables, all the other groups of goods and services appear to exhibit a high degree of convergence among pairs of inflation rates across provinces. This indicates that convergence in provincial inflation rates is widespread across COICOP groups of goods and services, irrespective of the tradables/non-tradables distinction.

All in all, a number of institutional, political and economic changes, which we assume, based on economic theory and empirical observance, to have become more intense since the late $70 \mathrm{~s}$, have caused a regime shift in the area under study, in the form of a straightforward spatial convergence in the Spanish inflation rates. Our work, besides capturing that phenomenon using several recent econometric techniques, has also sought to account for this fact by assessing a number of possible underlying factors. To sum up, in the second period studied we find that the idiosyncrasy of the different Spanish geographic units seems to become less important. Our study paves the way for more specific approaches on the results and potential underlying factors that our analysis has brought into light.

Acknowledgments The authors are particularly indebted to the Editors and the anonymous referees of this Journal for valuable comments and suggestions that led to a substantial improvement of the original manuscript. We also thank Stephen L. Parente, Julián Ramajo, J. Ignacio Silva, Ma Ángeles Caraballo, Diego Martínez, Daniel Oto-Peralías, seminar participants at Pablo de Olavide University, and participants at the $55^{\text {th }}$ Congress of the European Regional Science Association (Lisbon) and INFER Workshop on Applied Macroeconomics and Labour Economics (Seville), for valuable comments and suggestions. The authors acknowledge financial support from the Spanish Ministry of Science and Technology under grant ECO2009-13357, the Spanish Ministry of Economics and Competitiveness under grant ECO2012-35430, and the Andalusian Council of Innovation and Science under Excellence Project SEJ-4546 and PAI SEJ-513.

Open Access This article is distributed under the terms of the Creative Commons Attribution 4.0 International License (http://creativecommons.org/licenses/by/4.0/), which permits unrestricted use, distribution, and reproduction in any medium, provided you give appropriate credit to the original author(s) and the source, provide a link to the Creative Commons license, and indicate if changes were made.

\section{References}

Alberola E, Marqués JM (2001) On the evolution of relative prices and its nature at the regional level: the case of Spain. J Reg Sci 41(3):451-474

Álvarez LJ, Hernando I (2006) Price setting behaviour in Spain. Evidence from consumer price microdata. Econ Model 23(4):699-716 
Álvarez LJ, Burriel P, Hernando I (2010) Price setting behaviour in Spain: evidence from micro PPI data. Manag Decis Econ 31(2-3):105-121

Arestis P, Chortareas G, Magkonis G, Moschos D (2014) Inflation targeting and inflation convergence: international evidence. Int Financ Mark Inst Money 31(C):285-295

Bai J (2004) Estimating cross-section common stochastic trends in nonstationary panel data. J Econom 122(1):137-183

Bai J, Carrión-i-Silvestre JL (2009) Structural changes, common stochastic trends, and unit roots in panel data. Rev Econ Stud 76(2):471-501

Bai J, Ng S (2002) Determining the number of factors in approximate factor models. Econometrica $70(1): 191-221$

Bai J, Ng S (2004a) A PANIC attack on unit roots and cointegration. Econometrica 72(4):1127-1177

Bai J, Ng S (2004b) A new look at panel testing of stationarity and the PPP hypothesis. In: Andrews DW, Stock J (eds) Identification and inference in econometric models: essays in honor of Thomas $\mathbf{J}$. Rothenberg. Cambridge University Press, Cambridge, pp 426-450

Bai J, Ng S (2010) Panel unit root tests with cross-section dependence. Econom Theory 26(4):1088-1114 Baldwin R, Wyplosz C (2013) The economics of European integration, 4th edn. McGraw-Hill, London Banerjee A, Marcellino M, Osbat C (2005) Testing for PPP: should we use panel methods? Empir Econ 30(1):77-91

Beck GW, Hubrich K, Marcellino M (2009) Regional inflation dynamics within and across euro area countries and a comparison with the United States. Econ Policy 24(57):142-184

Bentolila S, Dolado JJ, Jimeno JF (2012) Reforming an insider-outsider labor market: the Spanish experience. IZA J Eur Labor Stud 1(4):1-29

Blake AP, Rule GR, Rummel OJ (2015) Inflation targeting and term premia estimates for Latin America. Latin Am Econ Rev 24(3):1-21

Blanchard OJ (2005) Fiscal dominance and inflation targeting: lessons from Brazil. In: Giavazzi F, Goldfajn I, Herrera S (eds) Inflation targeting, debt, and the Brazilian experience, 1999-2003. The MIT Press, Cambridge, pp 49-80

Breusch TS, Pagan AR (1980) The Lagrange multiplier test and its application to model specifications in econometrics. Rev Econ Stud 47(1):239-253

Busetti F, Fabiani S, Harvey A (2006) Convergence of prices and rates of inflation. Oxford Bull Econ Stat 68(supplement):863-877

Busetti F, Forni L, Harvey A, Venditti F (2007) Inflation convergence and divergence within the European Monetary Union. Int J Cent Bank 3(2):95-121

Caraballo MA, Dabús C (2013) Price dispersion and optimal inflation: the Spanish case. J Appl Econ 16(1):49-70

Caraballo MA, Usabiaga C (2009a) Testing nominal rigidities in an integrated economy: an application to Spain. In: Marques H, Souzakis E, Cerqueira P (eds) Integration and globalization. Challenges for developed and developing countries. Edward Elgar, Chentelham, pp 43-62

Caraballo MA, Usabiaga C (2009b) The relevance of supply shocks for inflation: the Spanish case. Appl Econ 41(6): :753-764

Caraballo MA, Usabiaga C (2009c) Análisis desagregado de la inflación española y andaluza. Instituto de Estadística de Andalucía, Sevilla

Carrión-i-Silvestre JL, Kim D, Perron P (2009) GLS-based unit root tests with multiple structural breaks under both the null and the alternative hypotheses. Econ Theor 25(6):1754-1792

Choi I (2001) Unit root tests for panel data. J Int Money Financ 20(2):249-272

Cuadrado-Roura JR (ed) (2010) Regional policy, economic growth and convergence. Lessons from the Spanish case. Springer-Verlag, Berlin

Cuadrado-Roura JR, Parellada M (eds) (2002) Regional convergence in the European Union: facts, prospects and policies. Springer-Verlag, Berlin

de Haan J (2010) Inflation differentials in the euro area: a survey. In: de Haan J, Berger H (eds) The European Central Bank at ten. Springer-Verlag, Berlin, pp 11-32

De la Fuente (2010) Series anuales de algunos agregados económicos y demográficos regionales, 1955-2009 (RegDat versión 2.3). Instituto de Análisis Económico (CSIC), mimeo

Debelle G, Lamont OA (1997) Relative price variability and evidence from U.S. cities. J Polit Econ 105(1):132-152

Dickey DA, Fuller WA (1979) Distribution of the estimators for autoregressive time series with a unit root. J Am Stat Assoc 74(366):427-431 
Drine I, Rault C (2003) Do panel data permit the rescue of the Balassa-Samuelson hypothesis for Latin American countries? Appl Econ 35(3):351-359

Elliot G, Rothenberg T, Stock JH (1996) Efficient tests of an autoregressive unit root. Econometrica 64(4):813-839

European Central Bank (2005) Monetary policy and inflation differentials in a heterogeneous currency area. Month Bul 61-77

Fabiani S, Druant M, Hernando I, Kwapil C, Landau B, Loupias C, Martins F, Mathä T, Sabbatini R, Stahl H, Stokman A (2006) What firms' surveys tell about price setting behavior in the Euro area. Int J Cent Bank 2(3):3-47

Fingleton B (ed) (2003) European regional growth. Springer-Verlag, Berlin

Galí J, Gertler M (1999) Inflation dynamics: a structural econometric approach. J Monet Econ 44(2):195-222

Galí J, López-Salido JD (2001) Una nueva curva de Phillips para España. Moneda y Crédito 212:265-310

García-Solanes J, Torrejón-Flores F (2005) Testing the Balassa-Samuelson hypothesis in two different groups of countries: OECD and Latin America. FEDEA, Documentos de Economía y Finanzas Internacionales (DEFI), No. 05/02

García-Solanes J, Torrejón-Flores F (2012) Inflation targeting works well in Latin America. CEPAL Rev 106(April):37-53

Gengenbach C, Palm FC, Urbain JP (2010) Panel unit root tests in the presence of cross-sectional dependencies: comparisons and implications for modelling. Econom Rev 29(2):111-145

Gómez F, Usabiaga C (2001) Las estimaciones del desempleo de equilibrio de la economía española: una panorámica. Revista de Economía Aplicada 9(27):103-129

Gómez-Aguirre M, Rodríguez-Chávez JC (2013a) Cambio estructural y convergencia de precios entre las principales ciudades de México. EconoQuantum 10(1):59-75

Gómez-Aguirre M, Rodríguez-Chávez JC (2013b) Convergencia de precios en México. CIMEXUS 8(2):97-108

Gozgor G (2013) Unemployment persistence and inflation convergence: evidence from regions of Turkey. Region Sect Econ Stud 13(1):55-64

International Monetary Fund (2015) Peru. Country Report No. 15/133

Jaumotte F, Morsy H (2012) Determinants of inflation in the euro area: the role of labor and product market institutions. International Monetary Fund (IMF), Working Paper No. 12/37

Jimeno JF, Bentolila S (1998) Regional unemployment persistence (Spain, 1976-1994). Labour Econ 5(1):25-51

Juselius K, Ordóñez J (2009) Balassa-Samuelson and wage, price and unemployment dynamics in the Spanish transition to EMU membership. Econ Open-Access Open Assess E J 3(2009-4):1-30

Kwiatkowski D, Phillips PCB, Schmidt P, Shin Y (1992) Testing the null hypothesis of stationarity against the alternative of a unit root: how sure are we that economic time series have a unit root? J Econom 54(1):159-178

Lee J, Strazicich MC (2001) Break point estimation and spurious rejections with endogenous unit root tests. Oxford Bull Econ Stat 63(5):535-558

Lee J, Strazicich MC (2003) Minimum Lagrange multiplier unit root test with two structural breaks. Rev Econ Stat 85(4):1082-1089

Lumsdaine RL, Papell DH (1997) Multiple trend breaks and the unit-root hypothesis. Rev Econ Stat $79(2): 212-218$

Maddala GS, Wu S (1999) A comparative study of unit root tests with panel data and a new simple test. Oxford Bull Econ Stat 61(s1):631-652

Maza A, Villaverde J (2011) EU regional convergence and policy: does the concept of region matter? J Policy Model 33(6):889-900

Mendoza W (2013) Milagro peruano: ¿Buena suerte o buenas políticas? Economía 36(72):35-90

Mishkin F (2000) Inflation targeting in emerging-market countries. Am Econ Rev (Papers and Proceedings) 90(2):105-109

Montuenga-Gómez VM (2002) Did the EMS encourage inflation convergence? Int Atl Econ Rev $8(2): 119-127$

Moon HR, Perron B (2004) Testing for a unit root in panels with dynamic factors. J Econom 122(1):81-126

Moon HR, Perron B (2007) An empirical analysis of non-stationarity in a panel of interest rates with factors. J Appl Econom 22(2):383-400 
$\mathrm{Ng} \mathrm{S}$, Perron P (1995) Unit root tests in ARMA models with data-dependent methods for the selection of the truncation lag. J Am Stat Assoc 90(429):268-281

$\mathrm{Ng} \mathrm{S}$, Perron P (2001) Lag length selection and the construction of unit root tests with good size and power. Econometrica 69(6):1519-1554

O'Connell P (1998) The overvaluation of purchasing power parity. J Int Econ 44(1):1-19

Park HJ, Fuller WA (1995) Alternative estimators and unit root tests for the autoregressive process. J Time Ser Anal 16(4):449-459

Perron P, Ng S (1996) Useful modifications to some unit root tests with dependent errors and their local asymptotic properties. Rev Econ Stud 63(3):435-463

Pesaran MH (2004) General diagnostic tests for cross section dependence in panels. Institute for the Study of Labor (IZA), Discussion Paper No. 1240

Pesaran MH (2007a) A pair-wise approach to testing for output and growth convergence. J Econom 138(1):312-355

Pesaran MH (2007b) A simple panel unit root test in the presence of cross-section dependence. J Appl Econom 22(2):265-312

Phillips PCB, Perron P (1988) Testing for unit roots in time series. Biometrika 75(2):335-346

Rabanal P (2009) Inflation differentials between Spain and the EMU: a DSGE perspective. J Money Credit Bank 41(6):1142-1166

Ramos-Francia M, Torres A (2005) Reducing inflation through inflation targeting: the Mexican experience. In: Langhammer RJ, Vinhas de Souza L (eds) Monetary policy and macroeconomic stabilization in Latin America. Springer, Berlin, pp 1-29

Restoy F, Vallés J, López-Salido JD (2005) Inflation differentials in EMU: the Spanish case. Moneda y Crédito 220:55-104

Rogers JH (2001) Price level convergence, relative prices, and inflation in Europe. Board of Governors of the Federal Reserve System (Trade and Financial Studies Section), FRB International Finance Discussion Paper No. 699

Rogers JH (2007) Monetary union, price level convergence, and inflation: how close is Europe to the USA? J Monet Econ 54(3):785-796

Romero-Ávila D, Usabiaga C (2009) The hypothesis of a unit root in OECD inflation revisited. J Econ Bus 61(2):153-161

Romero-Ávila D, Usabiaga C (2012) Disaggregate evidence on Spanish inflation persistence. Appl Econ 44(23):3029-3046

Sargan JD, Bhargava A (1983) Testing residuals from least squares regression for being generated by the Gaussian random walk. Econometrica 51(1):153-174

Shin Y (1994) A residual based test for the null of cointegration against the alternative of no cointegration. Econom Theory 10(1):91-115

Shin Y, Snell A (2006) Mean-group tests for stationarity in heterogeneous panels. Econom J 9(1):123-158

Sonora R (2005) City CPI convergence in Mexico. Rev Dev Econ 9(3):359-367

Stock J (1999) A class of tests for integration and cointegration. In: McFadden DL, Engle RF (eds) Cointegration, causality and forecasting: a festschrift in honor of Clive W.J. Granger. Oxford University Press, Oxford, pp 137-167

Winkelried D, Gutiérrez JE (2012) Dinámica inflacionaria regional y el esquema de metas de inflación en el Perú. Revista de Estudios Económicos 24(Diciembre):79-98

Yilmazkuday H (2013) Inflation targeting, flexible exchange rates and inflation convergence. Appl Econ 45(5):593-603 